\title{
A Summary of the Forebody High- Angle-of-Attack Aerodynamics Research on the F-18 and the X-29A Aircraft
}

Lisa J. Bjarke, John H. Del Frate, and David F. Fisher NASA Dryden Flight Research Facility, Edwards, California

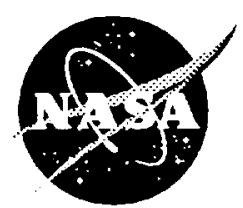

National Aeronautics and

Space Administration

Dryden Flight Research Facility

Edwards, California 93523-0273 



\title{
A Summary of the Forebody High-Angle-of-Attack Aerodynamics Research on the F-18 and the $X-29 A$ Aircraft
}

\author{
Lisa J. Bjarke, John H. Del Frate, and David F. Fisher \\ NASA Dryden Flight Research Facility
}

\begin{abstract}
High-angle-of-attack aerodynamic studies have been conducted on both the F-18 High Alpha Research Vehicle (HARV) and the X-29A aircraft. Data obtained include on- and off-surface flow visualization and static pressure measurements on the forebody. Comparisons of similar results are made between the two aircraft where possible. The forebody shapes of the two aircraft are different and the X-29A forebody flow is affected by the addition of nose strakes and a flight test noseboom. The forebody flow field of the F-18 HARV is fairly symmetric at zero sideslip and has distinct, well-defined vortices. The X-29A forebody vortices are more diffuse and are sometimes asymmetric at zero sideslip. These asymmetries correlate with observed zero-sideslip aircraft yawing moments.
\end{abstract}

\section{INTRODUCTION}

Personnel at NASA are currently involved in several high-angle-of-attack research programs, either as a part of the High Alpha Technology Program (HATP) or in joint research programs with other U.S. and international government agencies. The emphasis on high-angle-of-attack research resulted from the philosophy that modern fighter aircraft should be capable of controlled flight at high angles of attack. Two of the flight research programs at the NASA Dryden Flight Research Facility utilize the F-18 High Alpha Research Vehicle (HARV) and the X-29A aircraft. The F-18 HARV project is part of the HATP, which seeks to provide design guidelines and new concepts for vortex control on advanced, highly maneuverable aircraft at high angle of attack. The F-18 HARV serves as a validation and demonstration tool, using results from windtunnel and flight research to validate and update computational fluid dynamics (CFD) codes. The $X-29 A$ high-angle-of-attack program has been a joint program between the U.S. Air Force (Wright Laboratories and Flight Test Center), NASA, and Grumman Aircraft. The main emphasis of the X-29A high-angle-of-attack program has been in flight controls, handling qualities, and military utility and agility research.

Although the F-18 HARV and X-29A aircraft have been used for high-angle-of-attack research, the projects were operated from different philosophies. From the beginning of the F-18 HARV project there were plans to use flow visualization and pressure measurements to help define the aerodynamics of the aircraft at high angles of attack. Therefore, instrumentation to accomplish these objectives was incorporated early in the program and given a high priority. Conversely, on the X-29A project, flow visualization and pressure measurements were performed as part of a follow-on program. This follow-on program was initiated because some of the X-29A high-angle-of-attack flight characteristics were quite different than predicted. ${ }^{1}$ It was anticipated that a better understanding of the forebody aerodynamics could help explain the differences, given the success of the F-18 HARV experiments. $2,3,4$

The results from the F-18 HARV program include both on- and off-surface flow visualization and pressure measurements for the forebody and the leading-edge extension (LEX). In addition, surface flow visualization of the fuselage aft of the canopy, wing, and vertical tails are included. Flow visualization results are documented in Refs. 2 and 3 and 
pressure distribution results are found in Refs. 3 and 4. Results from the X-29A follow-on program include off-surface flow visualization and pressure measurements for the forebody and surface flow visualization of the wing and vertical tail. ${ }^{5,6}$ This paper will summarize the forebody aerodynamics research done on both aircraft and compare results where possible.

\section{AIRCRAFT DESCRIPTION}

F-18 HARV - The NASA HARV (Fig. 1) is a single-place preproduction $F-18$ aircraft built by the McDonnell Douglas (St. Louis, Missouri) and Northrop (Newbury Park, California) corporations. It is powered by two GE (General Electric, Lynn, Massachusetts) F404-GE-400 afterburning turbofan engines. The aircraft features a midwing with leadingand trailing-edge flaps. Leading-edge extensions (LEXs) are mounted on each side of the fuselage from the wing roots to just forward of the windscreen. The aircraft has twin vertical stabilizers canted out $20^{\circ}$ from the vertical and differential allmoving horizontal tails.

The aircraft is flown in the fighter escort configuration without stores. The production LEX fences have been removed from the aircraft. The aircraft carries no missiles and the wingtip Sidewinder missile launch racks have been replaced with special camera pods and wingtip airdata booms. ${ }^{7}$ The flight test noseboom has been removed from the aircraft and a NASA flush airdata system ${ }^{8}$ has been installed.

X-29A AIRCRAFT - The X-29A aircraft (Fig. 2(a)) is a technology demonstrator built by the Grumman Aircraft Corp. (Bethpage, New York). It is powered by one General Electric F404-GE-400 afterburning turbofan engine. The aircraft features a forward-swept wing, close-coupled canards, aft body strakes, and relaxed static stability. $1,9,10$ The wing incorporates double-hinged trailing-edge flaps that are scheduled as a function of free-stream Mach number, pressure altitude, and angle of attack $(\alpha)$. The aircraft has one vertical stabilizer and the aft body strakes incorporate flaps, which generally mirror the canard deflection. The all-movable canards deflect symmetrically and are scheduled as a function of free-stream Mach number, pressure altitude, and angle of attack. The X-29A aircraft uses an F$5 A$ forebody that was modified by shortening it by 11 in. and adding a nose strake and a flight test noseboom at the apex. ${ }^{9,10}$ The noseboom and strakes are indicated in Fig. 2(b).

\section{EXPERIMENTAL SETUP}

F-18 HARV - The off-surface flow visualization used a smoke generation system ${ }^{11,12}$ which ducted smoke to the forebody vortex cores at high angles of attack. The smoke was generated by pyrotechnic cartridges located inside the forebody. Twelve cartridges were carried on board. The number of cartridges ignited at one time could be varied, but typically four cartridges were used for each test point, resulting in three test points for each flight. Data were obtained at steady-state and dynamic flight conditions. Time-correlated onboard video and still cameras were used to document the off-surface flow visualization data. The camera locations and smoke generator system locations are indicated in Fig. 1. The smoke ports were located symmetrically on both sides of the aircraft near the nose and at the LEX apex, which is also indicated in Fig. 1.

The on-surface flow visualization utilized the emitted fluid technique. ${ }^{13-15}$ The emitted fluid technique used a small quantity (approximately 1 qt) of a solvent, propylene glycol monomethyl ether (PGME), and a toluene-based red dye. This fluid was emitted slowly from five circumferential rings on the F-18 HARV forebody (Fig. 3) while the aircraft was stabilized at the flight test conditions. As the fluid flowed back along the surface, the PGME evaporated, leaving the dye to mark the surface streamlines. This technique required the pilot to stabilize at the test conditions for 75 to 90 sec while the PGME evaporated and the dye was set. The resulting dye traces were photographed on the ground postflight, allowing one test point to be obtained for each flight.

Pressure measurements were made on the F-18 HARV forebody at the same five fuselage stations used for PGME visualization, forward of the canopy using rings of static pressure orifices at nondimensional length $(x / \ell)=0.015,0.038,0.071$, 0.126 , and 0.190 (Fig. 3). Details about the number of orifices in each ring can be found in Ref. 4 . This reference also contains details about the discontinuities and protrusions present on the F-18 HARV forebody.

X-29A AIRCRAFT - The X-29A forebody vortices were visualized with smoke using the same method employed on the F-18 HARV. The smokegenerating system was located in the $X-29 A$ forebody. However, since space was limited only four cartridges could be carried on board. A flexible duct routed the smoke from the cartridges to a " $Y$ " which diverted smoke to an exhaust port on each side of 


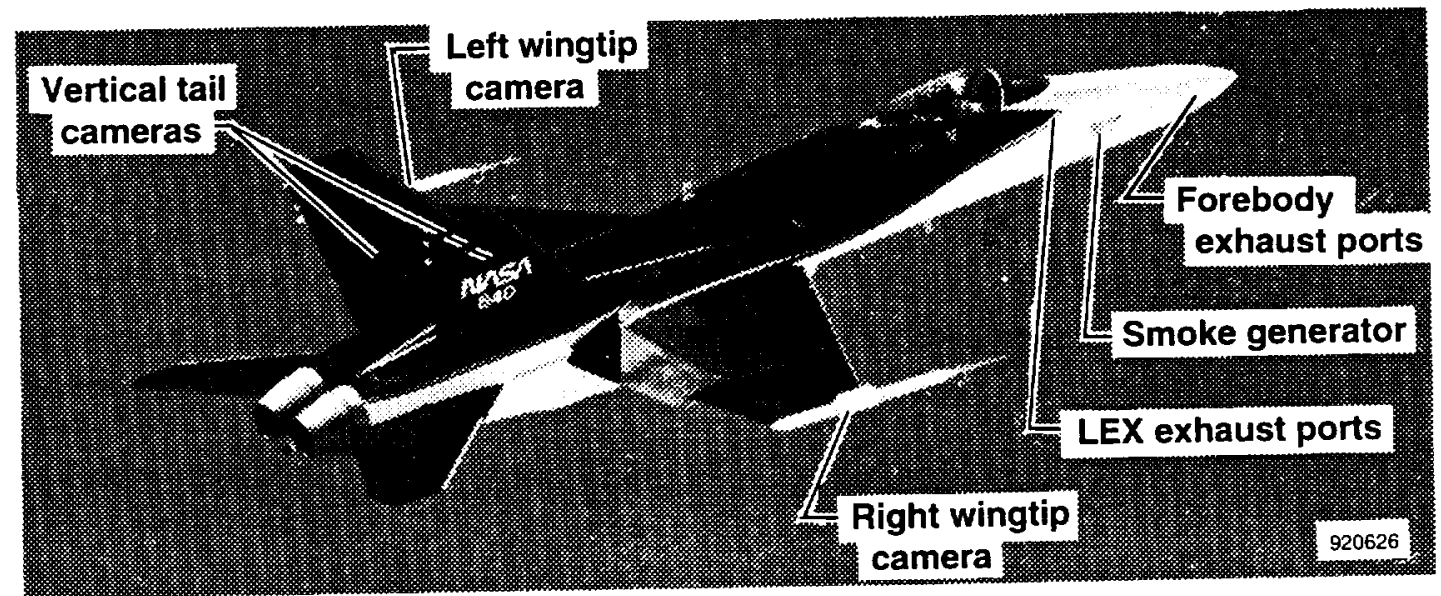

Fig. 1 F-18 HARV smoke generator system and camera locations.

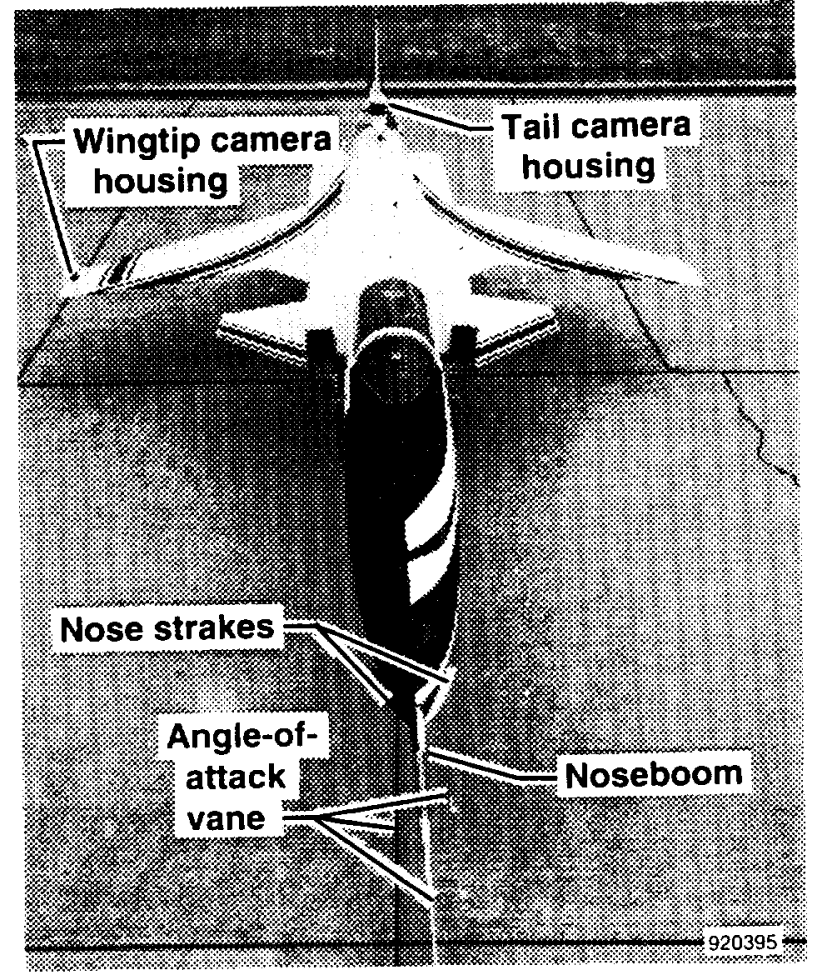

(a) Overall view.

Fig. $2 \times-29 A$ aircraft.

the aircraft (Fig. 2(b)). All four cartridges were required for adequate smoke density, resulting in one smoke test point for each flight. The right side of the forebody was painted flat black to provide the maximum contrast between the white smoke and the background when viewed by the wingtip cameras. The camera locations are indicated in Fig. 2(a).

Pressure measurements were made on the $X-29 A$ aircraft using circumferential rings of static pressure orifices. Four rings were installed ahead of the cockpit at $x / \ell=0.026,0.056,0.136$, and 0.201 (Fig. 4) and 202 orifices were installed. Gaps in the orifice distribution were caused by internal structure

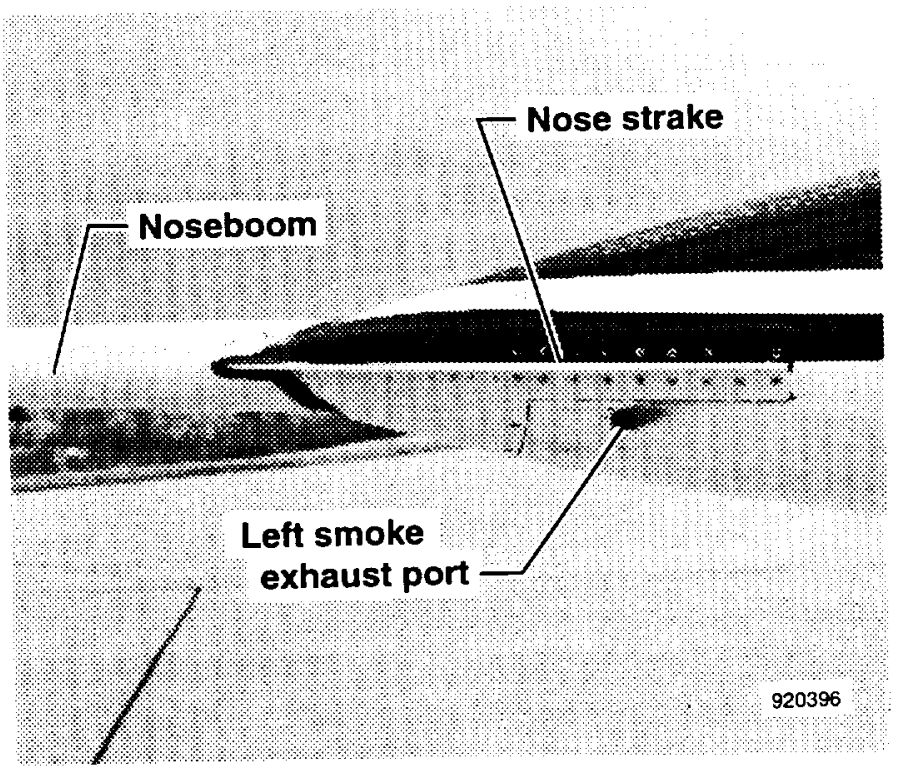

(b) Closeup of nose apex, side view.

Fig. 2 Concluded.

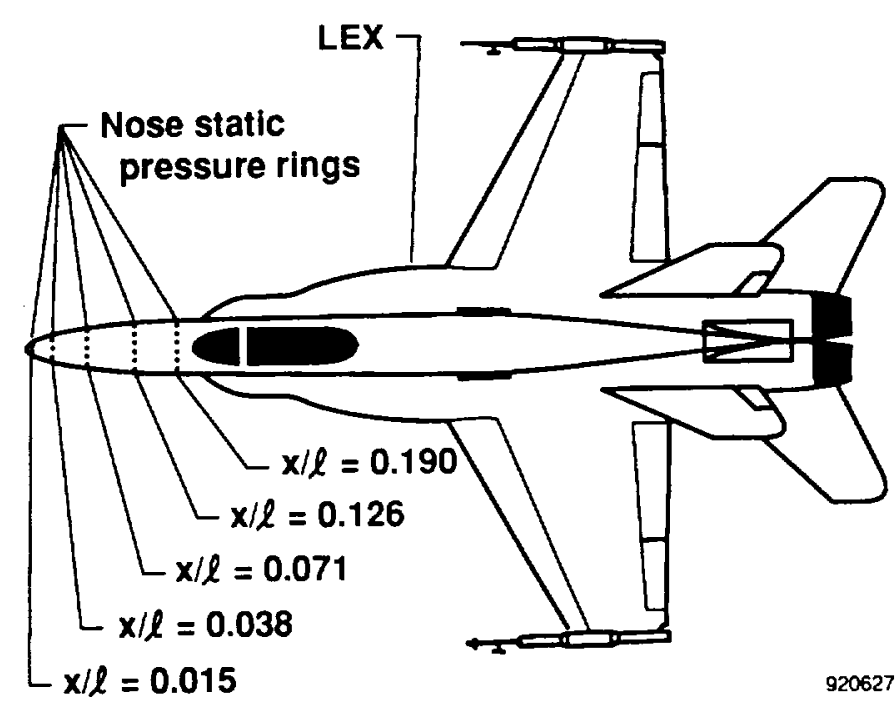

Fig. 3 F-18 HARV forebody pressure measurement stations. 
or lack of internal access. The X-29A forebody surface was considered to be smooth and free of protuberances typically found on operational aircraft.

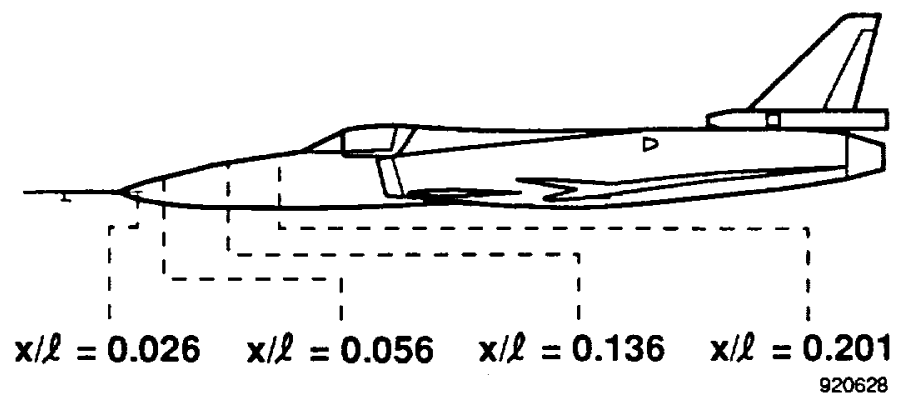

Fig. 4 Location of X-29A forebody pressure orifices.

\section{INSTRUMENTATION}

PRESSURE MEASUREMENTS - The instrumentation used for the F-18 HARV and the X-29A aircraft was quite similar. Each orifice on the forebody was connected to temperature-controlled electronic scanning pressure modules with $6 \mathrm{ft}$ of 0.062 in. i.d. pneumatic tubing. It was previously determined that $8 \mathrm{ft}$ of $0.062 \mathrm{in}$. flexible tubing would have a pneumatic lag of approximately $10 \mathrm{msec}$ at an altitude of approximately $20,000 \mathrm{ft}^{8}$ which was acceptable. Reference pressure was supplied by a reference tank vented to the F-18 HARV forward fuselage ${ }^{4}$ and by a small reference manifold vented inside the $X-29 A$ forebody. ${ }^{5}$ The reference pressure was monitored by a high-resolution digital absolute pressure transducer. The pressure transducers with each module were scanned sequentially 25 samples/sec and outputs were sampled by a 10-bit pulse code modulation (PCM) data system. In-flight zero differential pressure readings were taken before each test point and were used postflight to correct the data for calibration offsets. The forebody pressures were measured with approximately $216 \mathrm{lb} / \mathrm{ft}^{2}$ differential range pressure transducers with an estimated accuracy of approximately $1 \mathrm{lb} / \mathrm{ft}^{2}$.

FREE-STREAM AIRSPEED AND ALTITUDE Airspeed and altitude were measured on both aircraft using a specially designed swivel probe which self aligned with the local flow. A swivel probe was mounted on the left wingtip of both the F-18 HARV and $X-29 A$ aircraft. The probes were calibrated for Mach number and altitude. ${ }^{7}$

FREE-STREAM FLOW ANGLES - The F-18 HARV flow angle measurements were taken from the two wingtip booms. ${ }^{7}$ Angle of attack was measured by using a vane on the right wingtip boom. The measurement was then corrected for upwash and boom bending. Angle of sideslip was determined by averaging the left- and right-wingtip boom sideslip vane measurements corrected for angle of attack.

On the X-29A aircraft, angle of attack was a flight-critical input parameter to the triple-redundant flight-control system. Therefore, three independent angle-of-attack vanes were mounted on the noseboom. For high angles of attack, the vanes were calibrated using the aircraft inertial navigation system and meteorological analysis of rawinsonde balloon data. ${ }^{16,17}$ A single vane mounted on the noseboom was used to determine angle of sideslip.

\section{TEST CONDITIONS}

F-18 HARV - The on- and off-surface flow visualization data were obtained during $1-\mathrm{g}$ flight conditions. The nominal altitudes were between 20,000 and $30,000 \mathrm{ft}$ and the Mach numbers varied from approximately 0.2 to 0.4 . Angles of attack ranged from $10.0^{\circ}$ to approximately $54.0^{\circ}$ over the course of the flight program. This paper presents F-18 HARV flow visualization results only for $\alpha=26.0^{\circ}$ to $47.7^{\circ}$.

Surface pressure data presented were obtained in quasi-stabilized, 1-g flight maneuvers. Data were obtained at nominal altitudes of 20,000 and 45,000 $\mathrm{ft}$. The data presented are for $\alpha=10.0^{\circ}$ to $50.0^{\circ}$ and $0^{\circ}$ angle of sideslip $(\beta)$.

X-29A AIRCRAFT - The off-surface flow visualization data were obtained during $1-\mathrm{g}$ flight. The off-surface flow visualization data presented range from $\alpha=25.5^{\circ}$ to $50.5^{\circ}$. These test points were flown at altitudes between 17,000 and 30,000 ft.

Pressure distributions on the forebody were obtained at angles of attack from $15.0^{\circ}$ to $50.0^{\circ}$ during 1-g quasi-steady-state flight conditions at nominal altitudes of 20,000 and $40,000 \mathrm{ft}$. Pressure distributions at $\alpha>55.0^{\circ}$ were obtained on a single flight during a pullup-pushover maneuver of which $6.5 \mathrm{sec}$ were at $\alpha \geq 50.0^{\circ}$. As mentioned in the Instrumentation section, there was little lag in the pneumatic tubing between the orifice and the pressure transducer. At $\alpha \leq 55.0^{\circ}$ data from this dynamic maneuver were consistent with similar data from stabilized test points on other flights.

\section{RESULTS}

F-18 HARV OFF-SURFACE FLOW VISUALIZATION - Figure 5 shows wingtip view photographs of the F-18 HARV forebody vortices at two angles of attack. At $\alpha=29.5^{\circ}$ and $\beta=0.4^{\circ}$, the forebody vortex cores stay quite close to the fuselage, pass over 
the canopy, and continue straight aft. At $\alpha=47.0^{\circ}$ and $\beta=0.7^{\circ}$, the forebody vortex cores are farther away from the surface, arch higher over the canopy, and then are pulled down into the LEX vortex. ${ }^{2,3}$ At sideslip, the forebody vortex core position changes as illustrated in Fig. 6. This wingtip view photograph (and accompanying illustration) show the position of the forebody vortex cores at $\alpha=45.1^{\circ}$ and $\beta=-5.5^{\circ}$. The windward (left) forebody vortex core shifts to the right and away from the surface, travels over the canopy and straight aft. The leeward (right) forebody vortex core also shifts to the right, but this shift brings it into close proximity to the LEX vortex and draws it into the LEX vortex. ${ }^{2,3}$

$X-29 A$ OFF-SURFACE FLOW VISUALIZATION - Figure 7 presents wingtip photographs of the $X-29 A$ forebody vortices at $\alpha=25.0^{\circ}$ and $50.5^{\circ}$. On the $X-29 A$ forebody, the smoke entrained into the vortices is rather diffuse; the cores do not appear as tight and distinct as those seen on the F-18 HARV forebody. As angle of attack increases from $25.0^{\circ}$ to $50.5^{\circ}$, the vortices lift farther away from the surface aft of the canopy. Figure 8 is a photograph showing a vertical tail-view at $\alpha=33.2^{\circ}$ and $\beta=1.0^{\circ}$. The cores appear as two white lobes over the canopy. These lobes shift right and left as a pair with sideslip, and the windward vortex core shifts away from the aircraft surface. The lobes are separated by a dark "midplane" region. This midplane was considered to be representative of the angular position of the vortex system over the canopy. To analyze the behavior of this vortex system, the angular position was measured from the video images from the tail. Figure 9 illustrates how this angle, $\theta_{v}$, is defined. $\theta_{v}$ is the angle between the midplane and the vertical plane. It is defined to be positive to the right, as seen by the tail camera, and negative to the left. At each angle of attack investigated, $\theta_{v}$ was plotted as a function of sideslip. Although there was some scatter in the data, the relationship was fairly linear and a linear approximation was sketched through the data set.

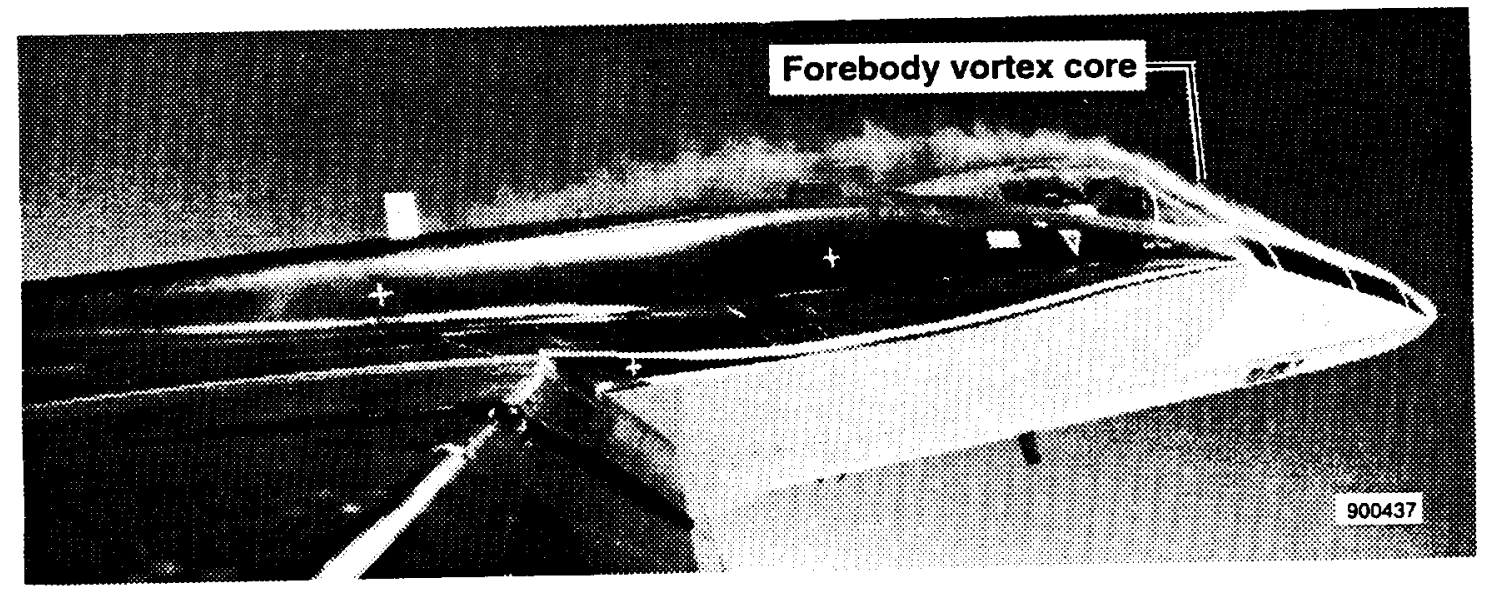

(a) $\alpha=29.5^{\circ}, \beta=0.4^{\circ}$.

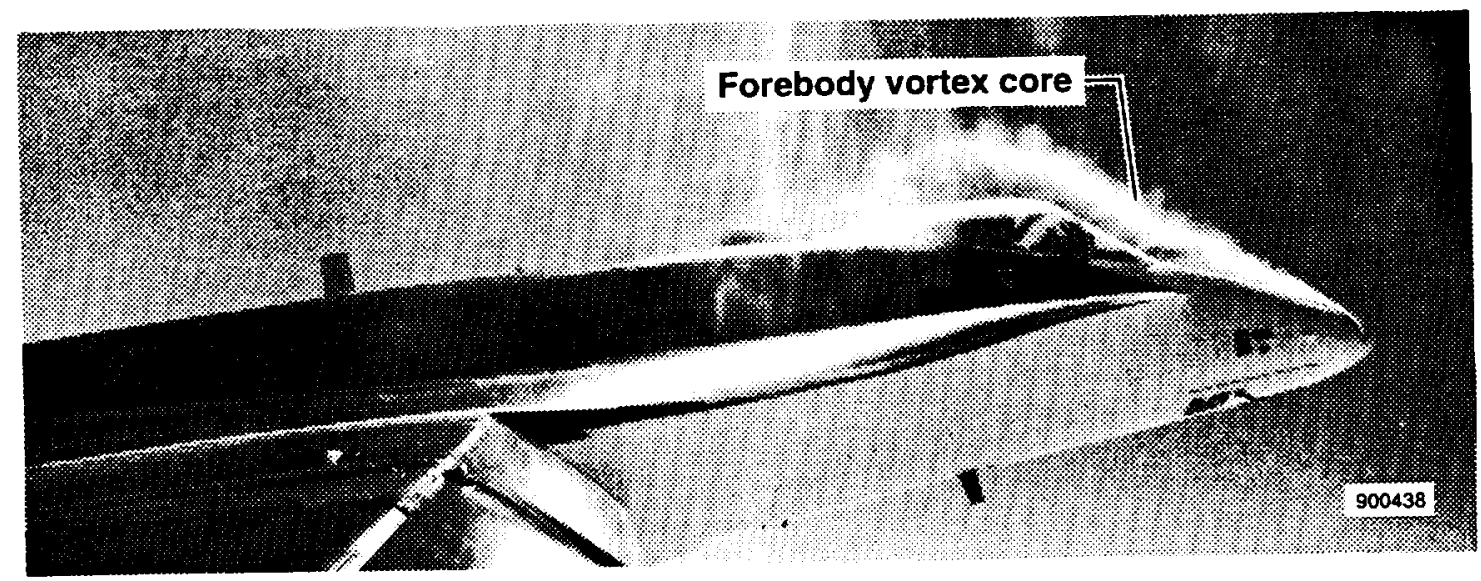

(b) $\alpha=47.7^{\circ}, \beta=0.7^{\circ}$.

Fig. 5 Wingtip view of F-18 HARV forebody vortices. 


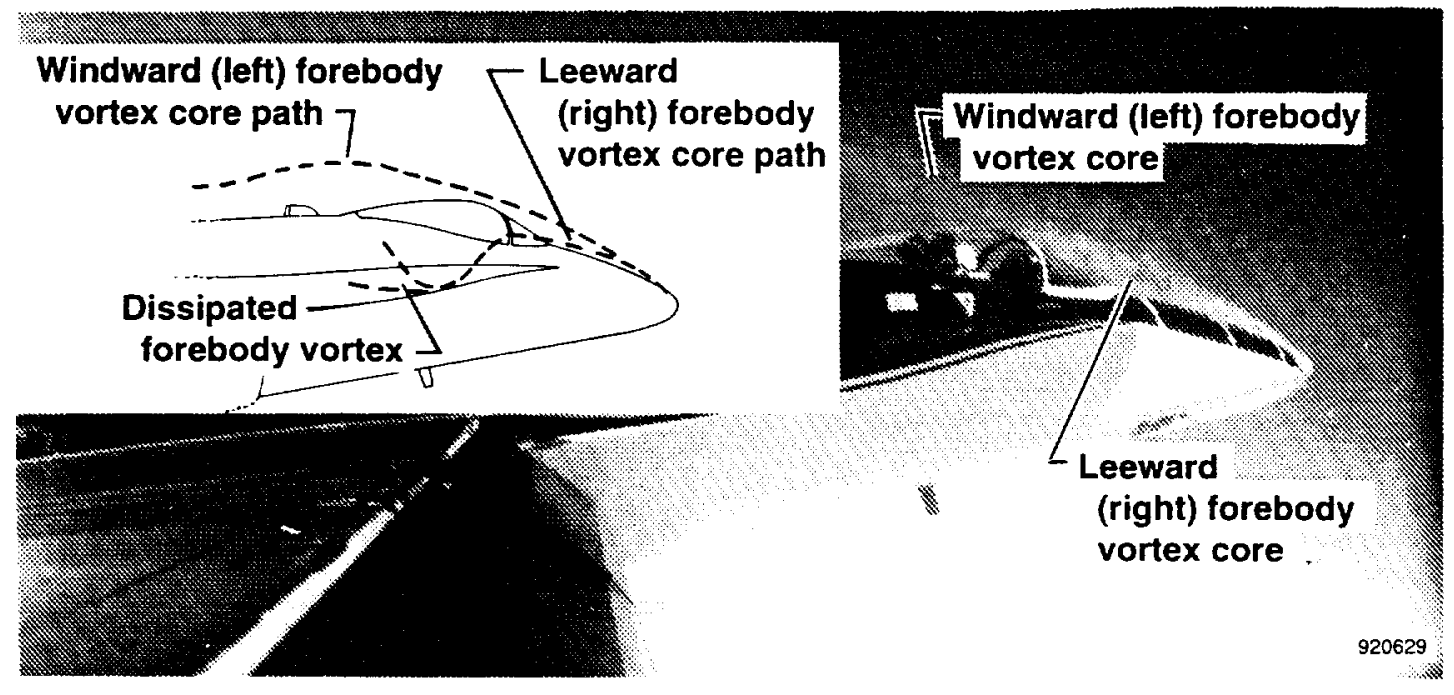

Fig. 6 Wingtip view of F-18 HARV forebody vortices in sideslip, $\alpha=45.1^{\circ}, \beta=-5.5^{\circ}$.

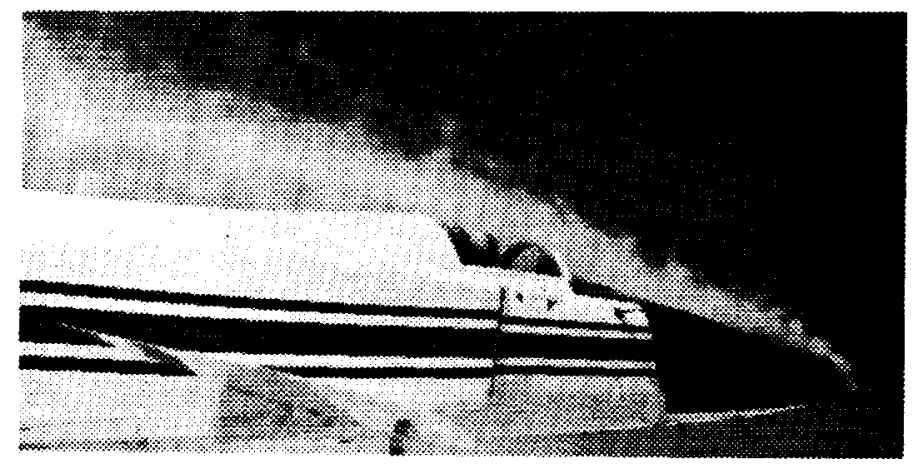

EC $91498-46$

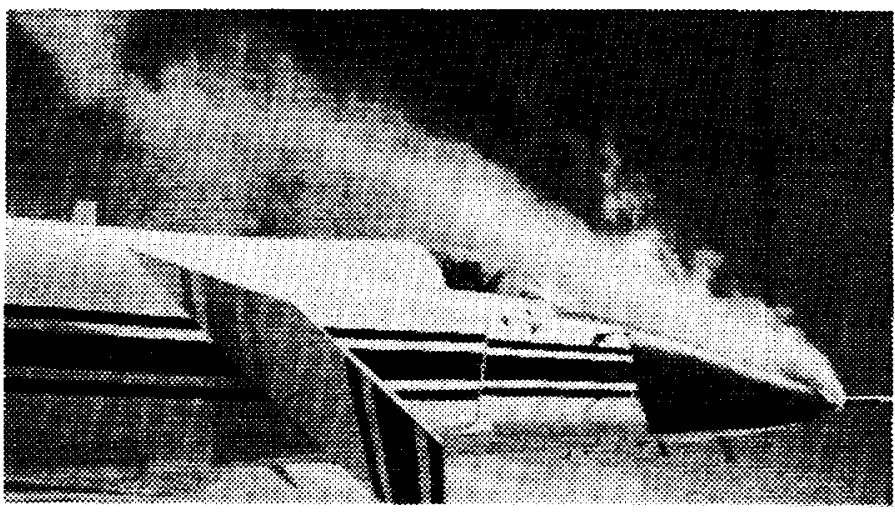

EC $91536-25$

Fig. 7 Wingtip view of X-29A forebody vortices.

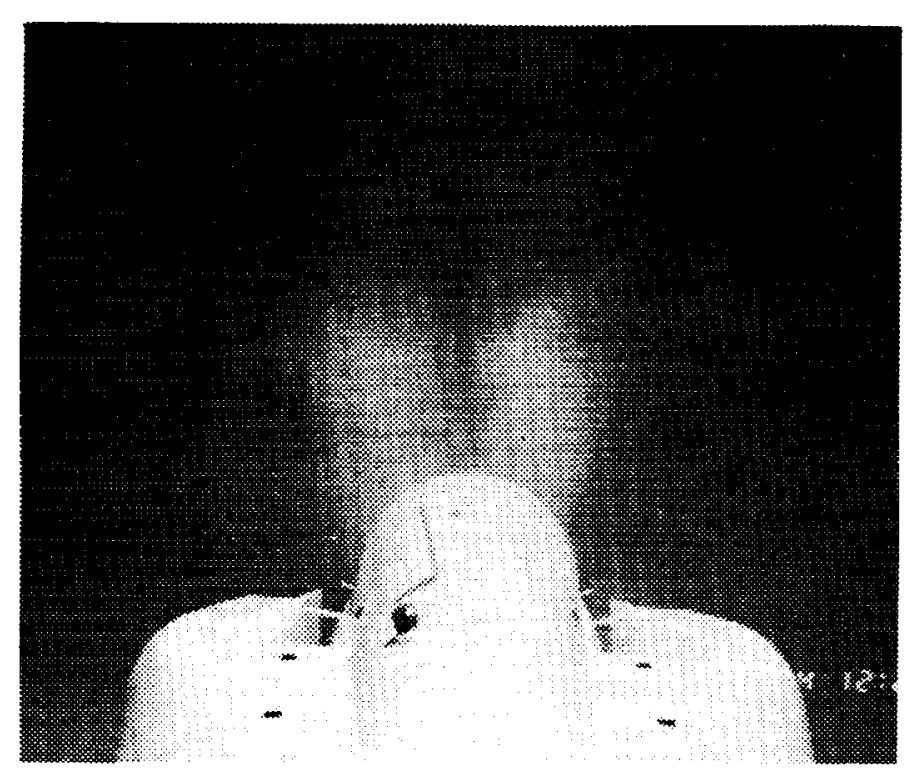

EC 91 390-33

Fig. 8 Tail camera view of X-29A forebody vortices, $\alpha=33.2^{\circ}, \beta=1.0^{\circ}$.

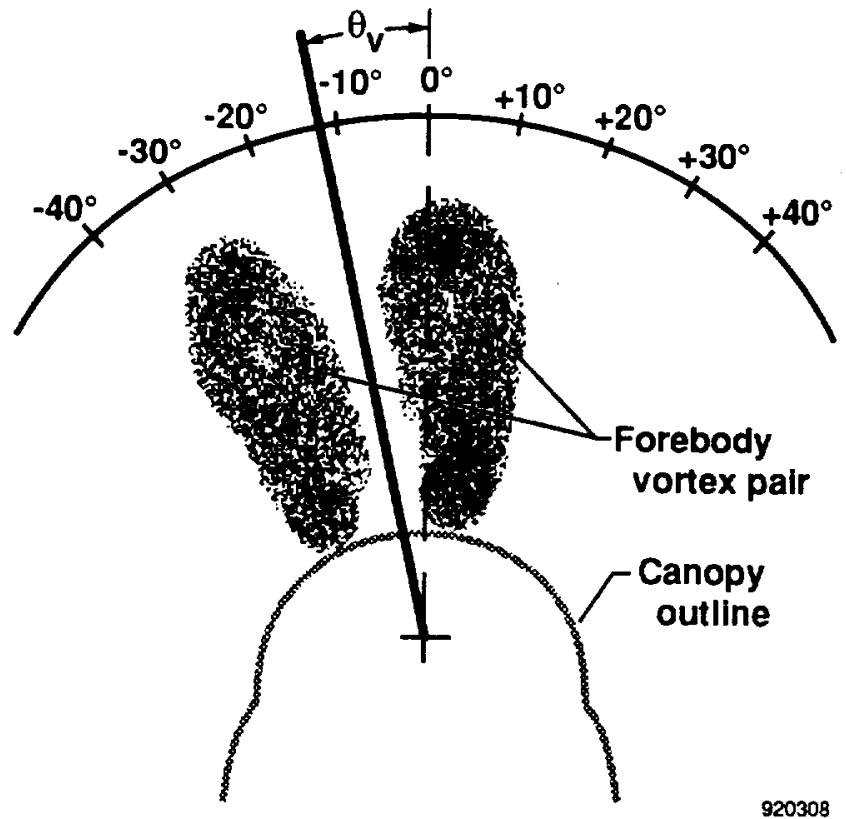

Fig. $9 \mathrm{X}-29 \mathrm{~A}$ forebody-vortex measurement technique. 
Figure 10 shows these linear approximations at angles of attack ranging from $\alpha=25.5^{\circ}$ to $50.5^{\circ}$. All the slopes of these lines are similar, but the bias is not always zero at zero sideslip. When the vortex pair is shifted in one direction, for example to the left, there is more attached flow on the right side of the forebody. This would produce lower pressure on the right side than the left, causing a net force to the right. Conversely, when the vortices are shifted to the right, a nose-left force results. This hypothesis is supported by comparing the X-29A yawing moment at $\beta=0^{\circ}\left(C_{n_{0}}\right)$ with the vortex angular position at $\beta=0^{\circ}$ as shown in Fig. 11.

The F-18 HARV and the X-29A aircraft have different forebody shapes. The apex of the F-18 HARV forebody has a circular cross section which transitions to an elliptical cross section with the major axis along the vertical. The X-29A forebody is actually a modified F-5A forebody. The cross section is also elliptical; however, the major axis is along the horizontal. Further aft on the forebody, this elliptical cross section becomes squared at the major axis.

The F-18 HARV and X-29A forebody vortices do not behave in the same manner at high angles of attack. The F-18 HARV forebody vortices have fairly well-defined cores, which arch over the canopy and get pulled down into the LEX vortices at the higher angles of attack. The X-29A forebody vortices are more diffuse (as visualized by the smoke generating system) with no well-defined cores visible. The $X-29 A$ vortex path is fairly straight aft of the canopy. In sideslip, the F-18 HARV windward vortex shifts away from the surface and the leeward vortex shifts toward the surface and interacts with the LEX vortex. ${ }^{2,3}$ With sideslip, the X-29A forebody vortex cores generally shift left and right as a pair and over the forebody; there are no major shifts in the position vertically. The respective forebody cross-sectional differences between the F-18 HARV and $X-29 A$ aircraft may be a cause for the differences observed. However, the noseboom and nose strakes on the X-29A forebody have an effect as well. On the $X-29 A$ forebody there is no additional strong vortex system (similar to the F-18 HARV LEX vortices) to interact with the forebody vortices and affect their vertical position.

SURFACE FLOW VISUALIZATION - TWo forms of surface flow visualization were used during the F-18 HARV program. The first was the emitted fluid technique (on the forebody) and the second was flow cones and tutts (on the wing, fuselage, and vertical tails). The emitted fluid technique was not used during the X-29A program because of lack of space and electrical concerns. However, flow cones and tufts were used on the canard, wing, aft fuselage, and vertical tail. This section will only discuss F-18 HARV surface flow visualization results obtained using the emitted fluid technique. Results from the F-18 HARV and X-29A flow cone and tuft observations can be found in Refs. 2 (F-18 HARV) and $6(X-29 A)$.

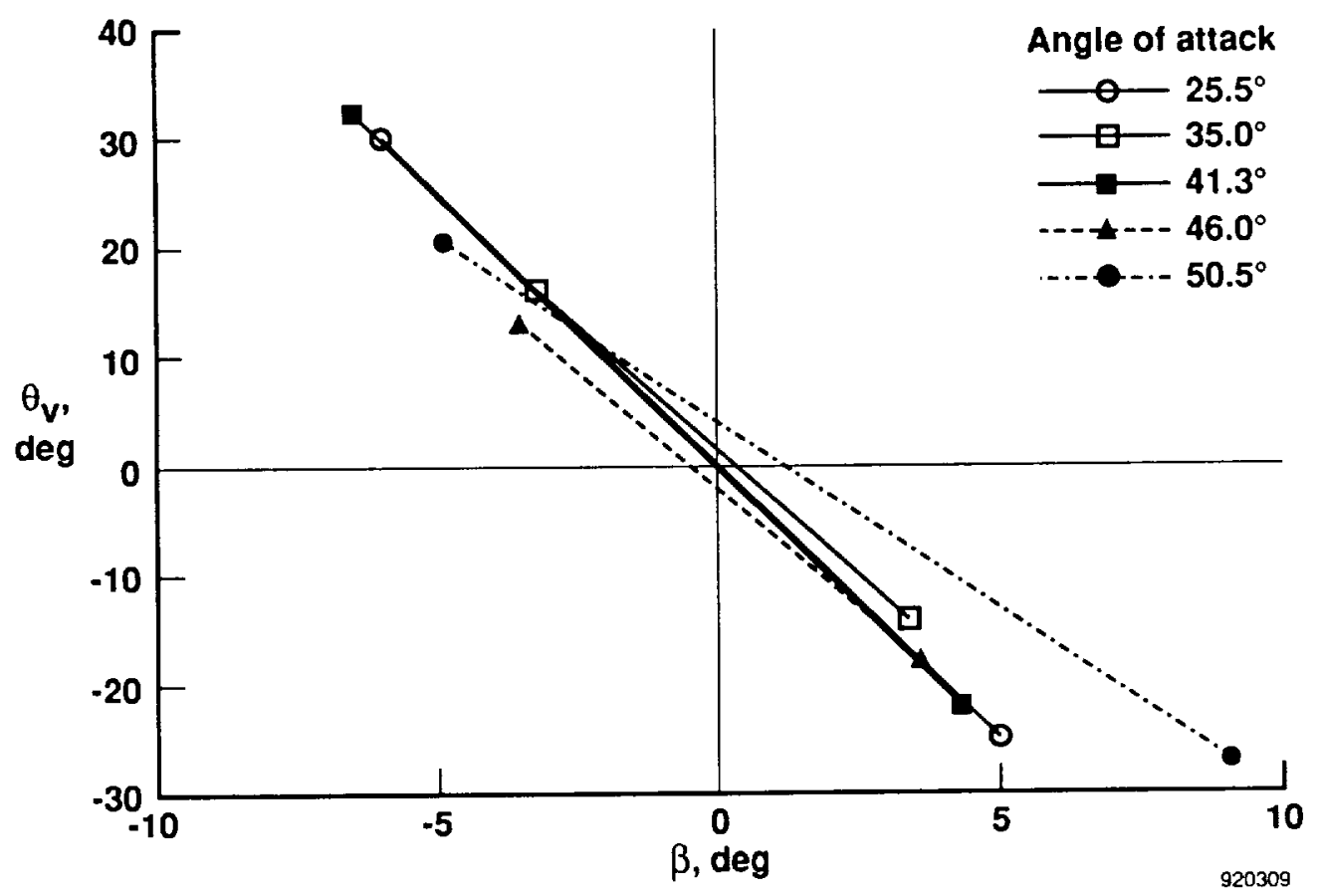

Fig. 10 X-29A approximated forebody-vortex system position as a function of sideslip. 


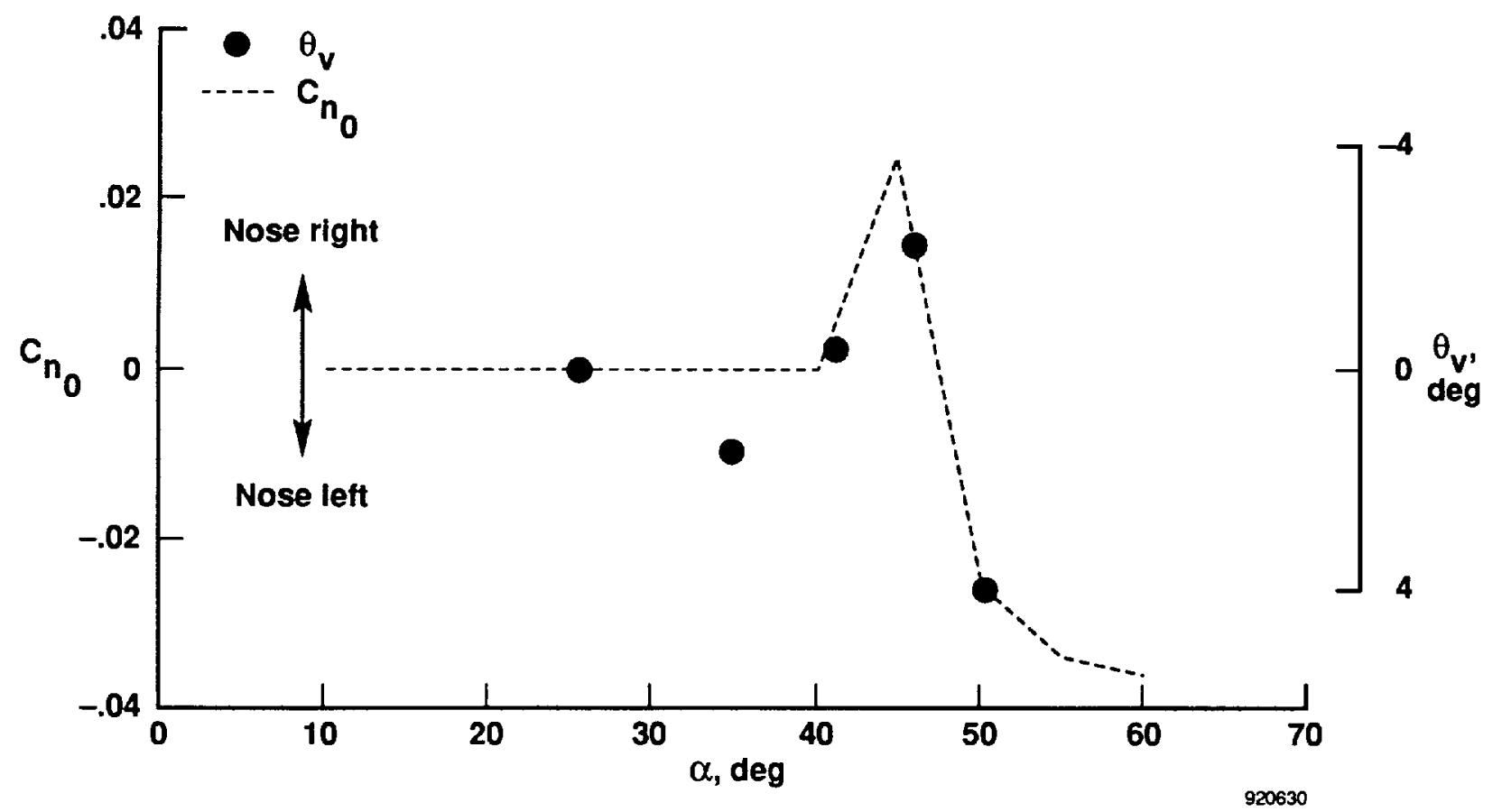

Fig. 11 Comparison of X-29A yawing moment at $\beta=0^{\circ}$ and forebody vortex system position $\left(\theta_{v}\right)$.

Results from the emitted fluid technique were photographed postflight, thus only one test point could be obtained during each flight. This technique was used for surface flow visualization on the forebody and the LEX. The emitted fluid technique marks surface streamlines with the red dye left behind after the PGME evaporated during the test point. Where the flow streamlines merge, lines of flow separation are defined. Conversely, where the streamlines diverge, lines of reattachment are defined. Since the fluid flows away from the reattachment line, reattachment is visible only in the dye near a source of fluid.

Figure 12 shows two photographs of the forebody taken after the emitted fluid technique was used at $\alpha=26.0^{\circ}$. Both the primary and secondary forebody separation lines are visible and are nearly symmetric. Only the primary vortex had been visible during smoke flow visualization. This may be because the secondary vortices form farther aft on the forebody than the smoke ports and are weaker. The emitted fluid results do not indicate the presence of a vortex until approximately $x / \ell=0.126$ at this angle of attack. There are some small kinks or curves in streamlines, which indicate a laminar separation bubble (LSB). This will be discussed in more detail later.

Figure 13 shows an example of surface flow visualization on the forebody at $\alpha=47.0^{\circ}$. The primary differences between $\alpha=47.0^{\circ}$ and $\alpha=$ $26.0^{\circ}$ are that the streamlines are more smeared at the higher angles of attack and that the secondary vortex separation lines have moved forward. At $\alpha=47.0^{\circ}$, they appear at approximately $x / \ell=$ 0.038 as opposed to $x / \ell=0.126$ at $\alpha=26.0^{\circ}$. The smearing of the streamlines is simply because the flight conditions were more difficult to hold steady at the higher angles of attack. Although the separation lines are smeared, they are nearly symmetric.

Further and more definitive indications of boundary-layer transition on the forebody were evident at $\alpha=47.0^{\circ}$ (Fig. 13). The effect of the boundary-layer transition is seen in the closeup view in Fig. 14. A large dye puddle is noted extending intermittently from $\theta=240^{\circ}$ at $x / \ell=0.015$ to approximately $x / \ell=0.075$ and $\theta=247^{\circ}$. Though not presented, symmetric results were obtained on the left side at $\theta=129^{\circ}$ and $113^{\circ}$ at $x / \ell=0.015$ and 0.075 , respectively. It is believed that these puddles are the result of an LSB with boundary-layer transition occurring downstream. The dye puddle did not occur at the screwhead protuberances around the plugged smoker port. (These screwhead protuberances would cause premature transition.) In addition, the fluid windward of the LSB flowed toward the LSB and the fluid leeward of the LSB flowed away. This indicates that the flow reattached turbulently past the very localized LSB and that this is not the primary vortex separation line.

F-18 HARV FOREBODY PRESSURES - Figure 15 shows the F-18 HARV forebody pressure distributions over an angle-of-attack range from 


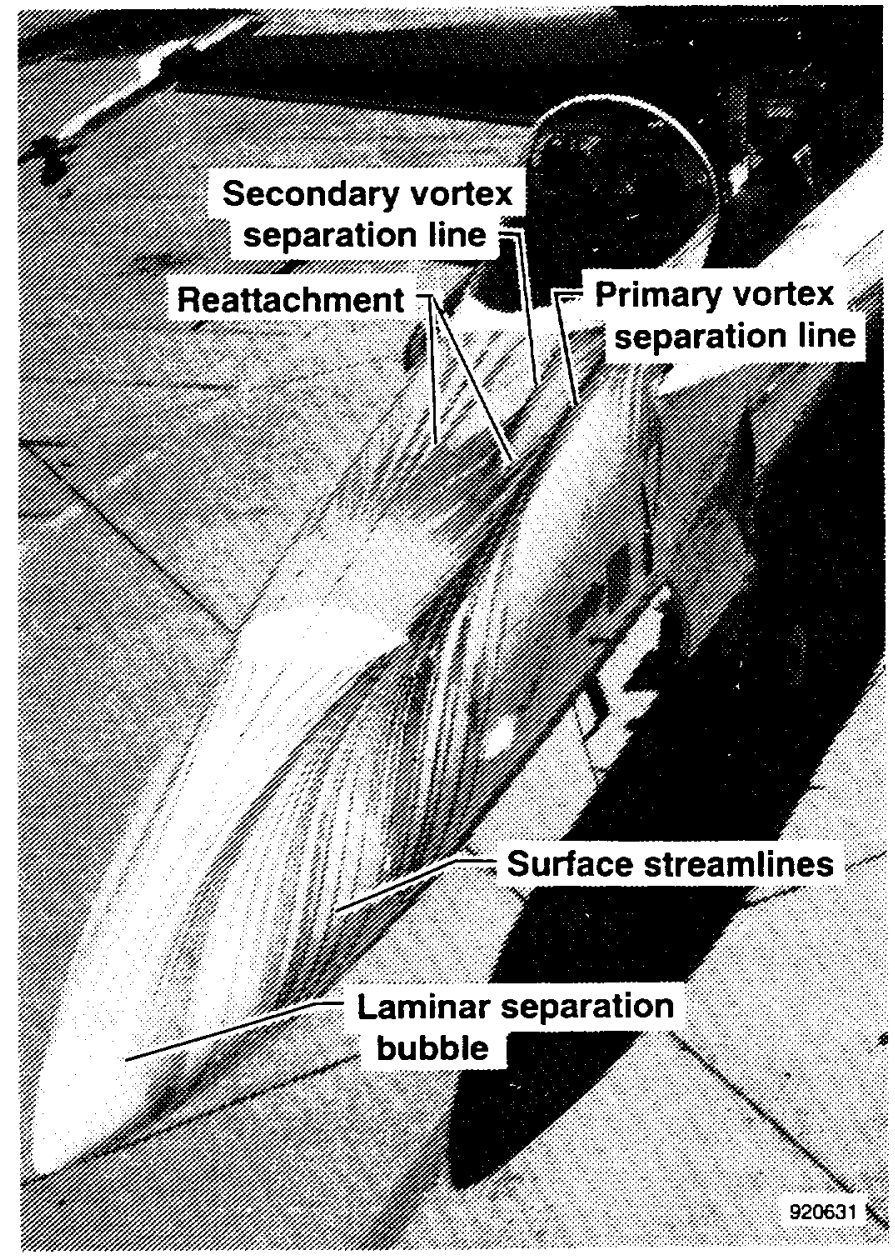

(a) 1/4 view.

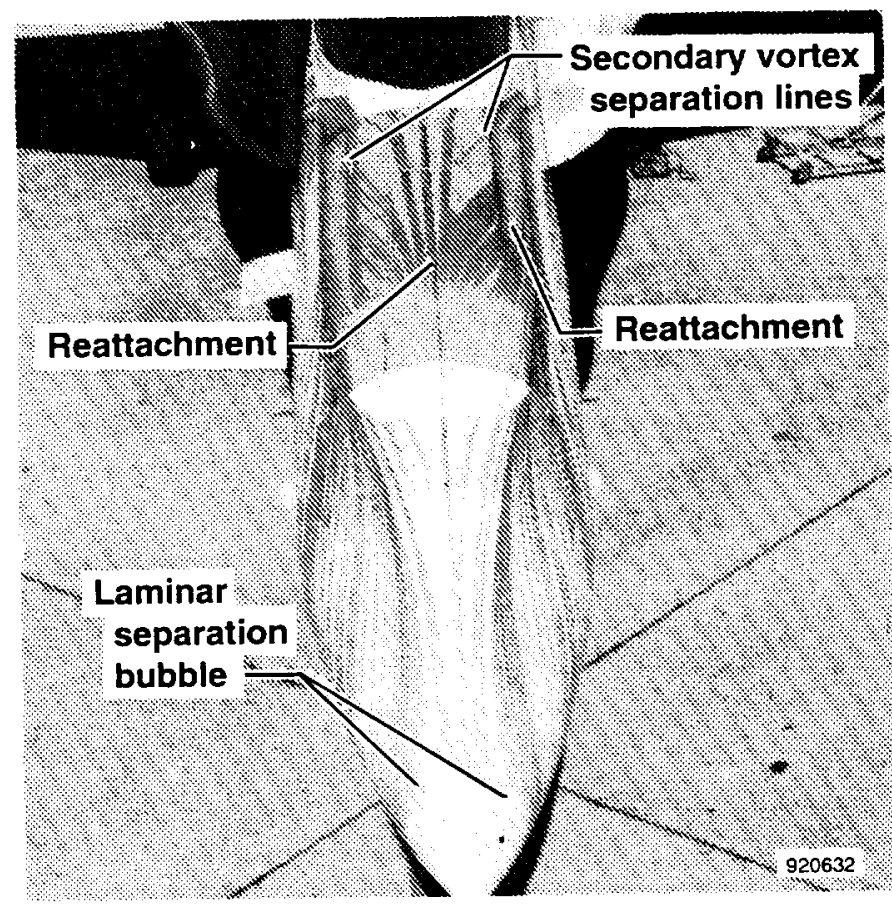

(b) Head-on view.

Fig. 12 Surface flow visualization on F-18 HARV forebody, $\alpha=26.0^{\circ}$.

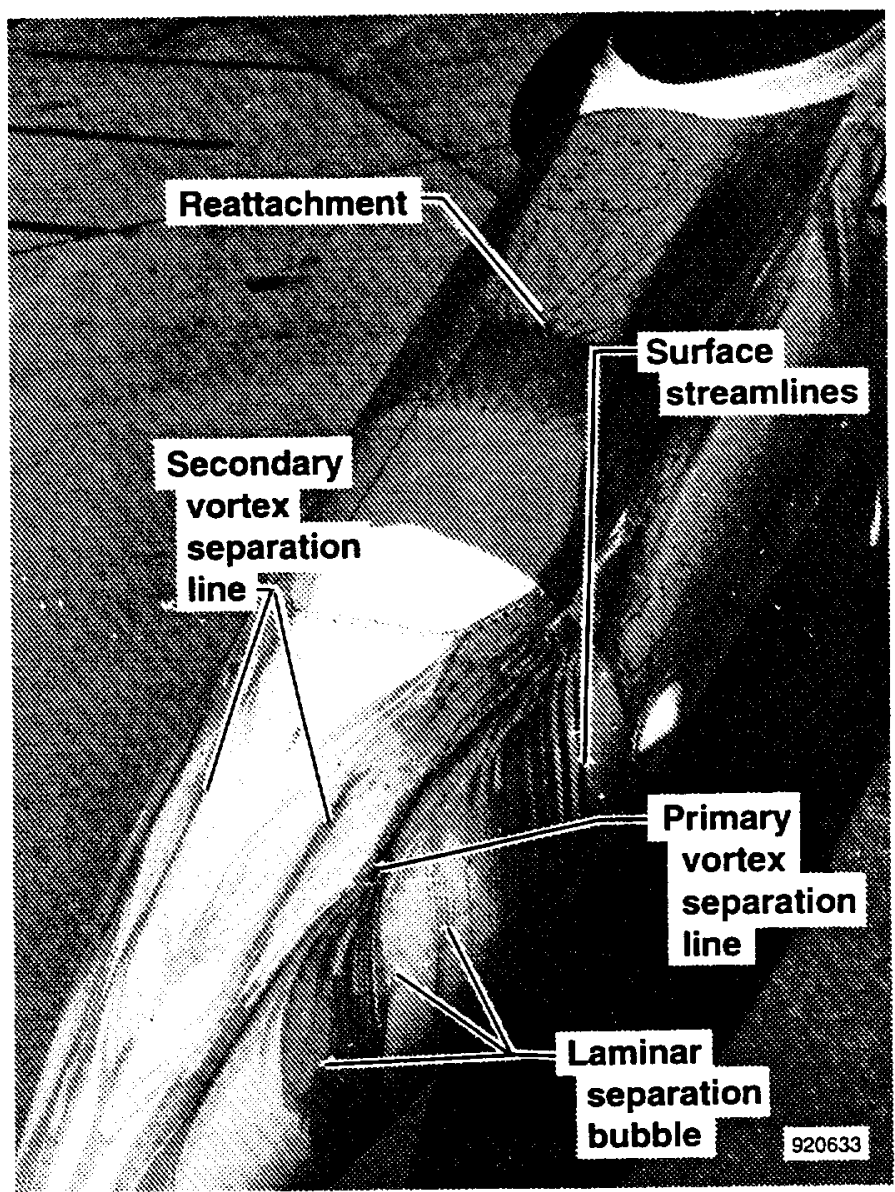

(a) 1/4 view.

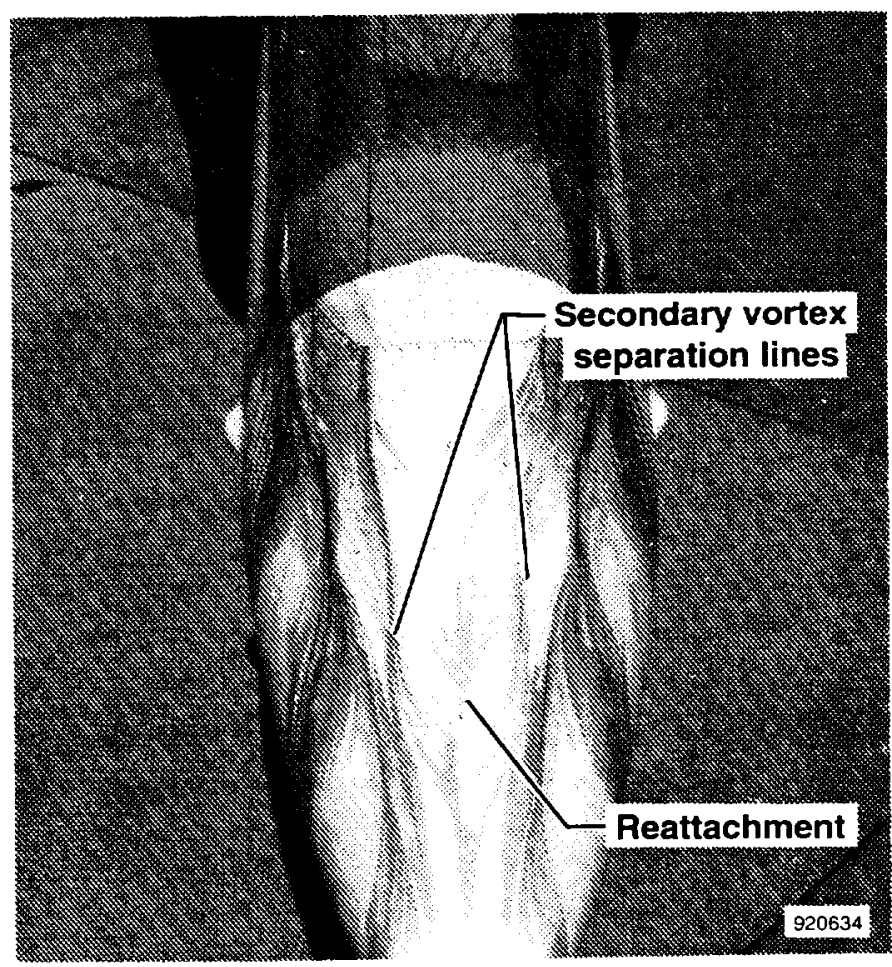

(b) Head-on view.

Fig. 13 Surface flow visualization on F-18 HARV forebody, $\alpha=47.0^{\circ}$. 


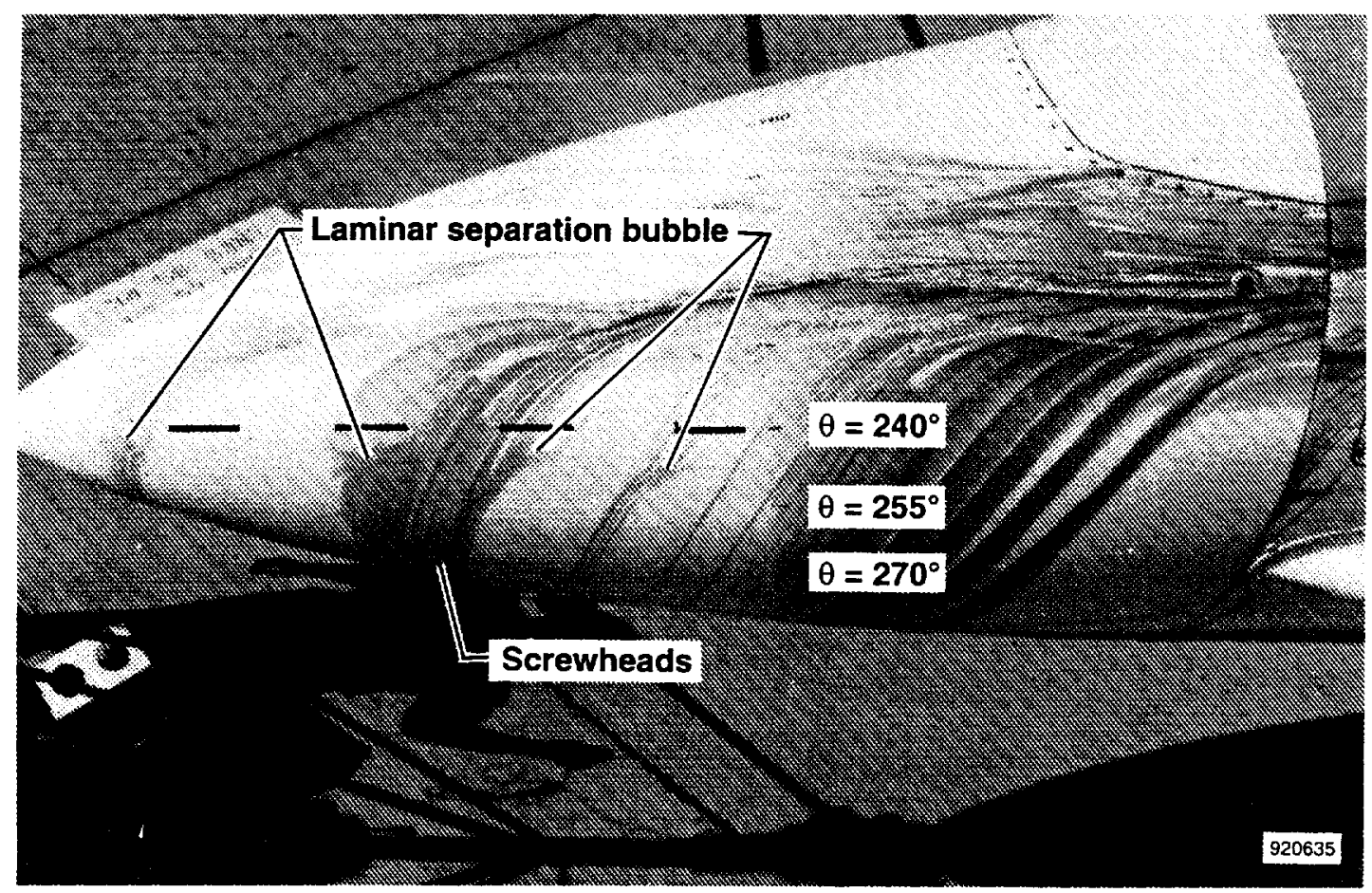

Fig. 14 Closeup of nose cone of F-18 HARV, $\alpha=47.0^{\circ}$.

$10.0^{\circ}$ to $50.0^{\circ}$. On the forward three rows $(x / \ell=$ $0.015,0.038$, and 0.071 ) the flow accelerating around the forebody produces a pair of maximum suction peaks starting at $\alpha=19.7^{\circ}$ (Figs. 15(a)(c)). The angular location of these peaks were at $\theta \approx 100^{\circ}$ to $120^{\circ}$ and $\theta \approx 240^{\circ}$ to $260^{\circ}$. These suction peaks became more pronounced with increasing angle of attack. The "footprints" of the primary vortex cores are first visible at $x / \ell=0.038$ and 0.071 at $\alpha=34.3^{\circ}$ (Figs. 15(b)-(c)). The footprints are indicated by the suction peaks at $\theta=168^{\circ}$ and $192^{\circ}$. As angle of attack increases, these peaks become more negative. The pressure distributions for the three fonward rows are symmetric at $\beta=0^{\circ}$ at $\theta \approx 180^{\circ}$ up to $\alpha=50.0^{\circ}$ (Figs. $15(\mathrm{a})-(\mathrm{c})$ )).

As shown in Fig. 15(d), at $x / \ell=0.126$, the maximum suction peaks are indicated at $\theta=70^{\circ}$ and $290^{\circ}$. The sharp peaks in the pressure distribution appearing at $\alpha \geq 19.7^{\circ}$ at $\theta=90^{\circ}$ to $110^{\circ}$ and $\theta=270^{\circ}$ to $250^{\circ}$ are caused by local separation behind antenna covers. The angular location of these points moves up as angle of attack increases. The forebody vortex core footprints are first indicated at $\alpha=25.8^{\circ}$ at $\theta=160^{\circ}$ and $200^{\circ}$. These footprint peaks become increasingly negative as angle of attack increases to $45.4^{\circ}$, then diminish at $\alpha=50.0^{\circ}$ indicating the vortices are lifting away from the surface. Aside from the differences caused by local protuberances or discontinuities, the pressure distributions are generally symmetric at $\theta \approx 180^{\circ}$.
As shown in Fig. $15(\mathrm{e})$, at $x / \ell=0.190$, the maximum suction peaks have moved up to $\theta=120^{\circ}$ and $240^{\circ}$ because of the influence of the LEX. The LEX apex is located only 13 in. aft of this fuselage station at $\theta=123^{\circ}$ and $237^{\circ}$. The maximum suction peaks are diminished from those seen at $x / \ell=0.126$ and forward. The primary vortex footprints at $x / \ell=0.190$ are indicated at $\theta=165^{\circ}$ and $195^{\circ}$ at $\alpha>25.8^{\circ}$, but are smaller in magnitude than those at $x / \ell=0.126$, indicating they are even farther off the surface. The pressure peaks on $x / \ell=0.190$ at $\theta \approx 48^{\circ}$ to $60^{\circ}$ and $\theta \approx 300^{\circ}$ to $312^{\circ}$ for $\alpha \geq 34.3^{\circ}$ are caused by local separation behind the aircraft production pitot-static probes.

X-29A FOREBODY PRESSURES - Figure 16 shows the $X-29 A$ forebody pressure distributions over an angle-of-attack range from $14.9^{\circ}$ to $66.2^{\circ}$. A schematic of the forebody cross section is also shown. The pressure distributions at $x / \ell=0.026$ (Fig. 16(a)) are different from those seen on the F-18 HARV (Fig. 15) in that the maximum suction peak is caused by the nose strake vortex rather than where the flow accelerates around the forebody. These suction peaks are at $\theta \approx 108^{\circ}$ and $252^{\circ}$ and generally increase in magnitude with angle of attack. The suction peaks are symmetric up to $\alpha=30.1^{\circ}$, at $\alpha>30.1^{\circ}$ asymmetries develop (Fig. 16(a)). The magnitude of the port suction peak is greater than the starboard suction peak, indicating 


$$
90^{\circ}-180^{\circ}-0^{\circ}-270^{\circ}
$$

Starboard

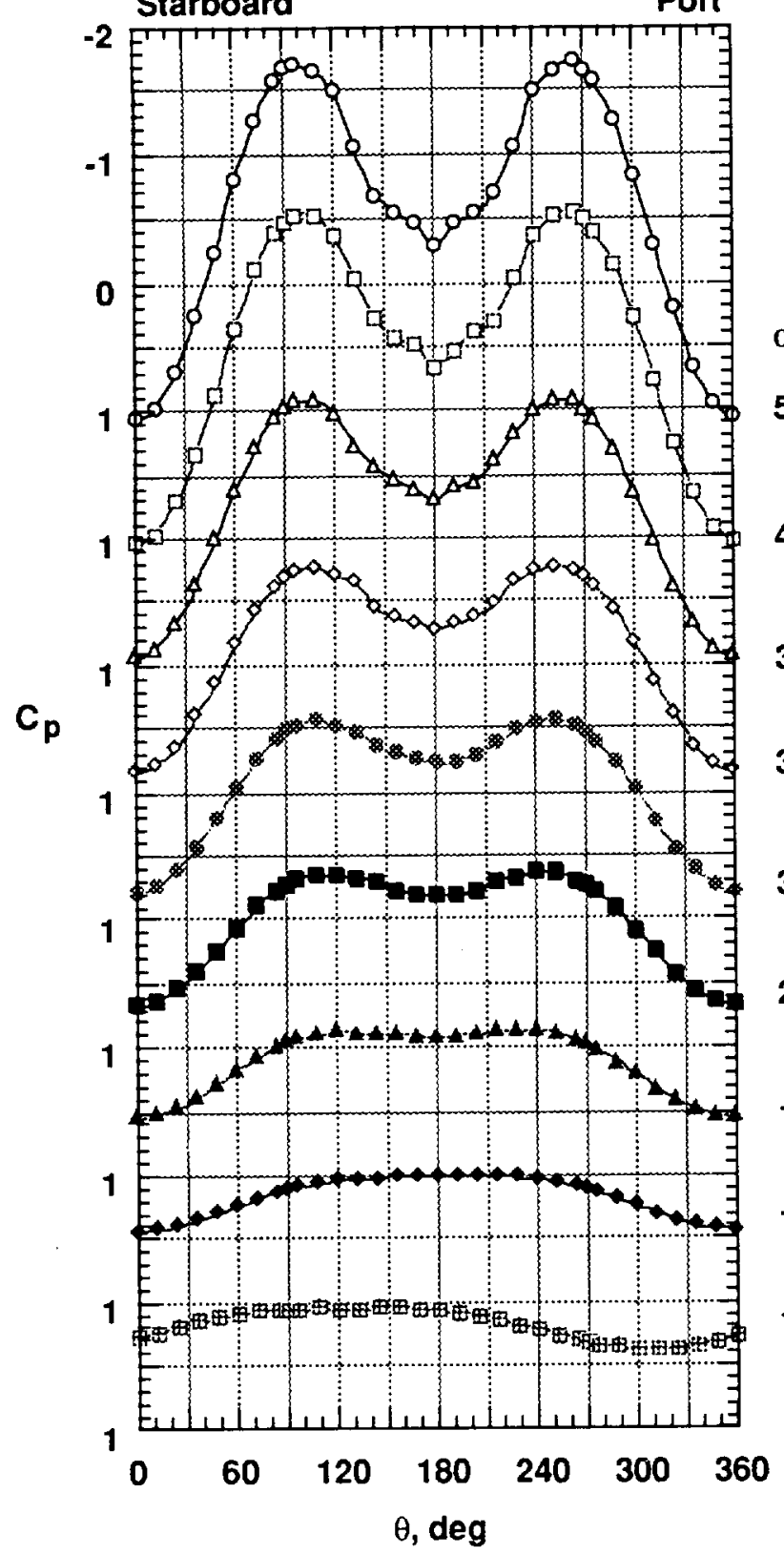

(a) $x / \ell=0.015$.

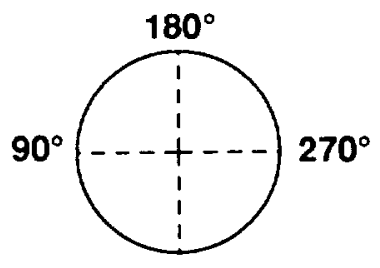

$\theta=0^{\circ}$

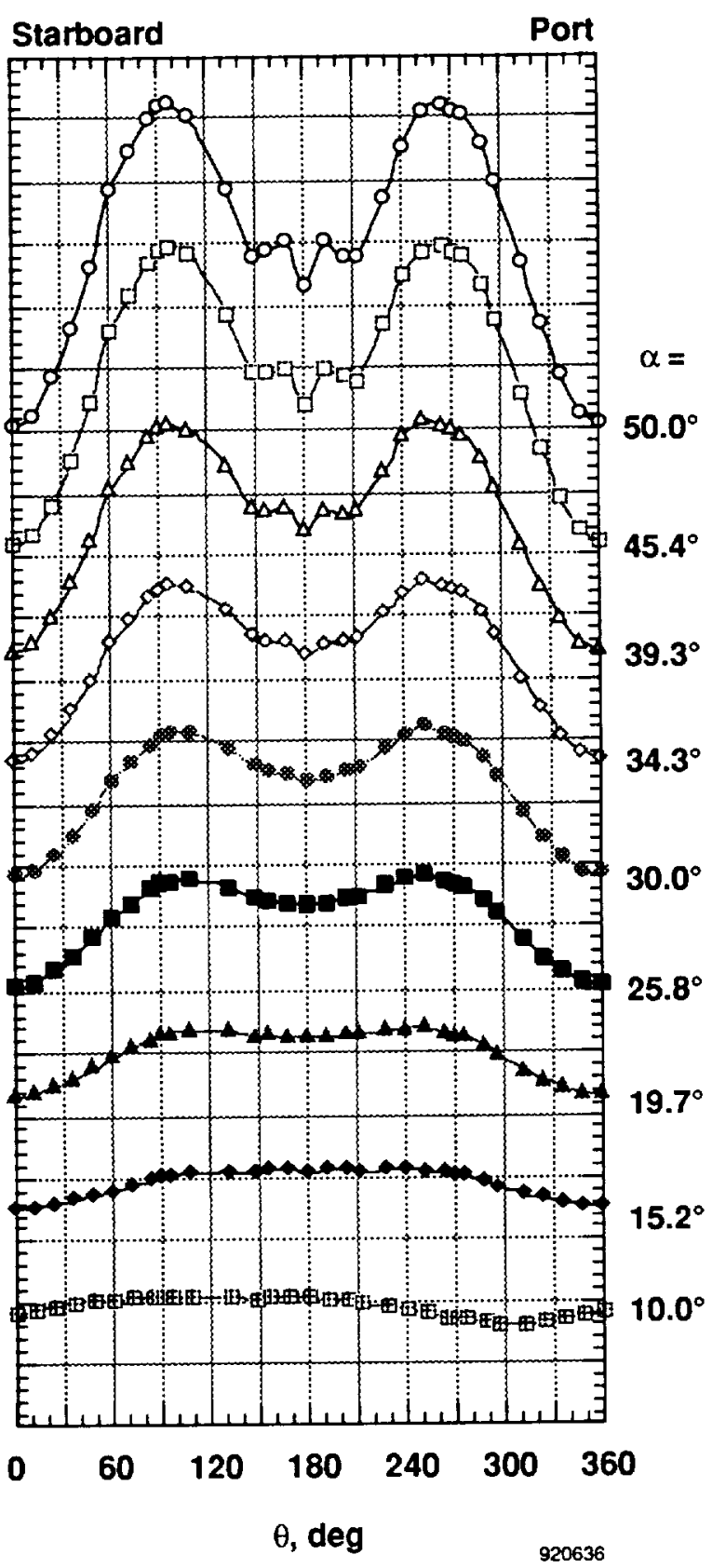

(b) $x / \ell=0.038$.

Fig. 15 Effect of angle of attack on F-18 HARV forebody pressures. 

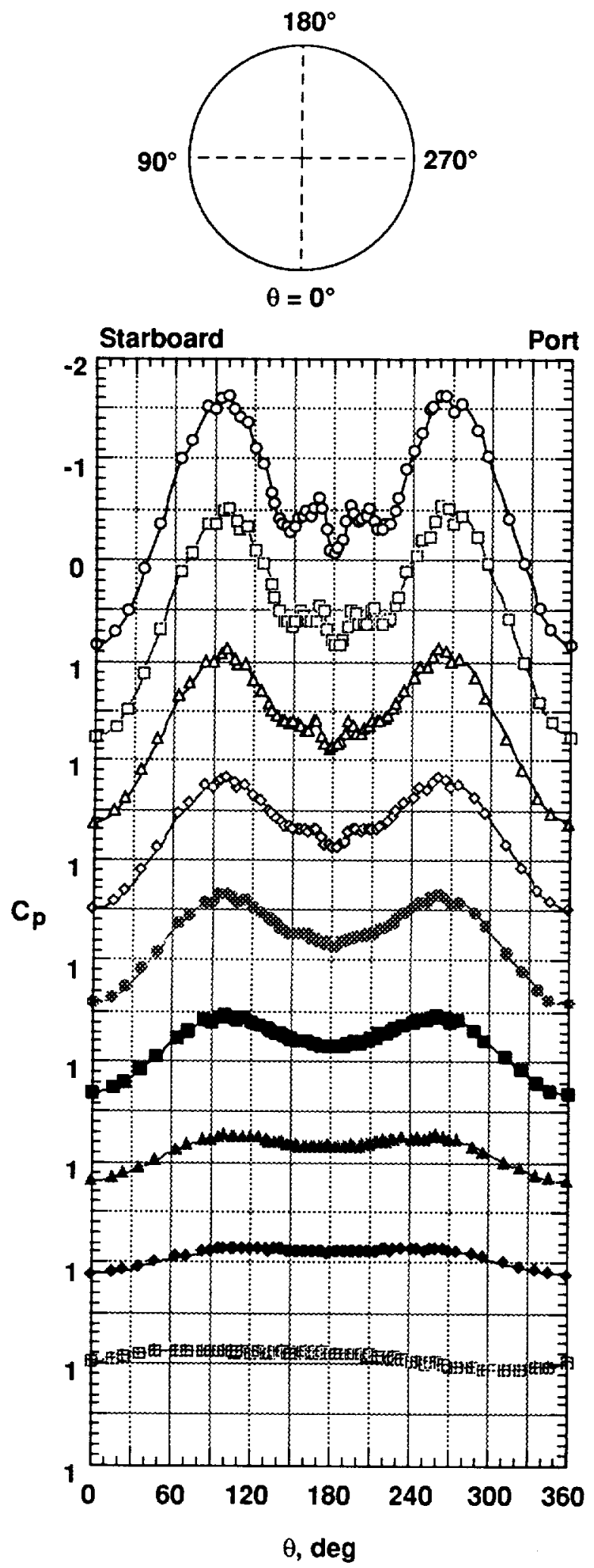

(c) $x / \ell=0.071$.
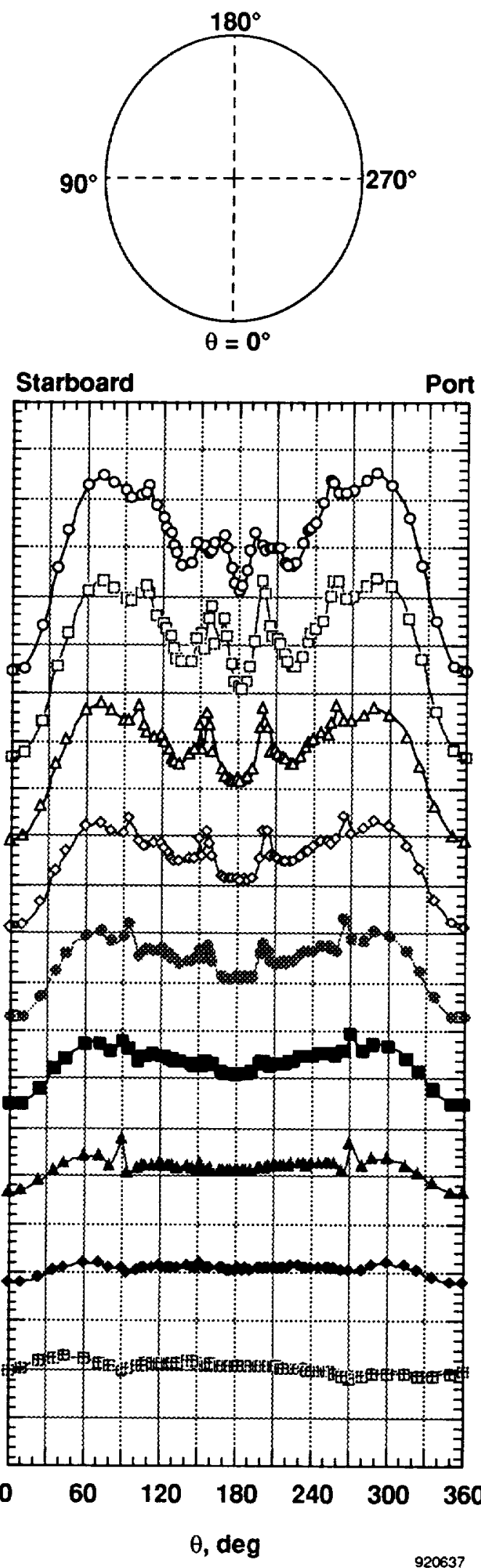

$\alpha=$

$50.0^{\circ}$

$45.4^{\circ}$

$45.4^{\circ}$

$39.3^{\circ}$

$34.3^{\circ}$

$30.0^{\circ}$

$25.8^{\circ}$

$19.7^{\circ}$

$15.2^{\circ}$

$10.0^{\circ}$

(d) $x / \ell=0.126$.

Fig. 15 Continued. 


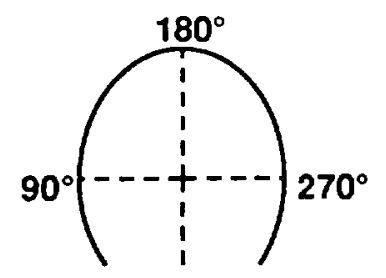

$$
\theta=0^{\circ}
$$

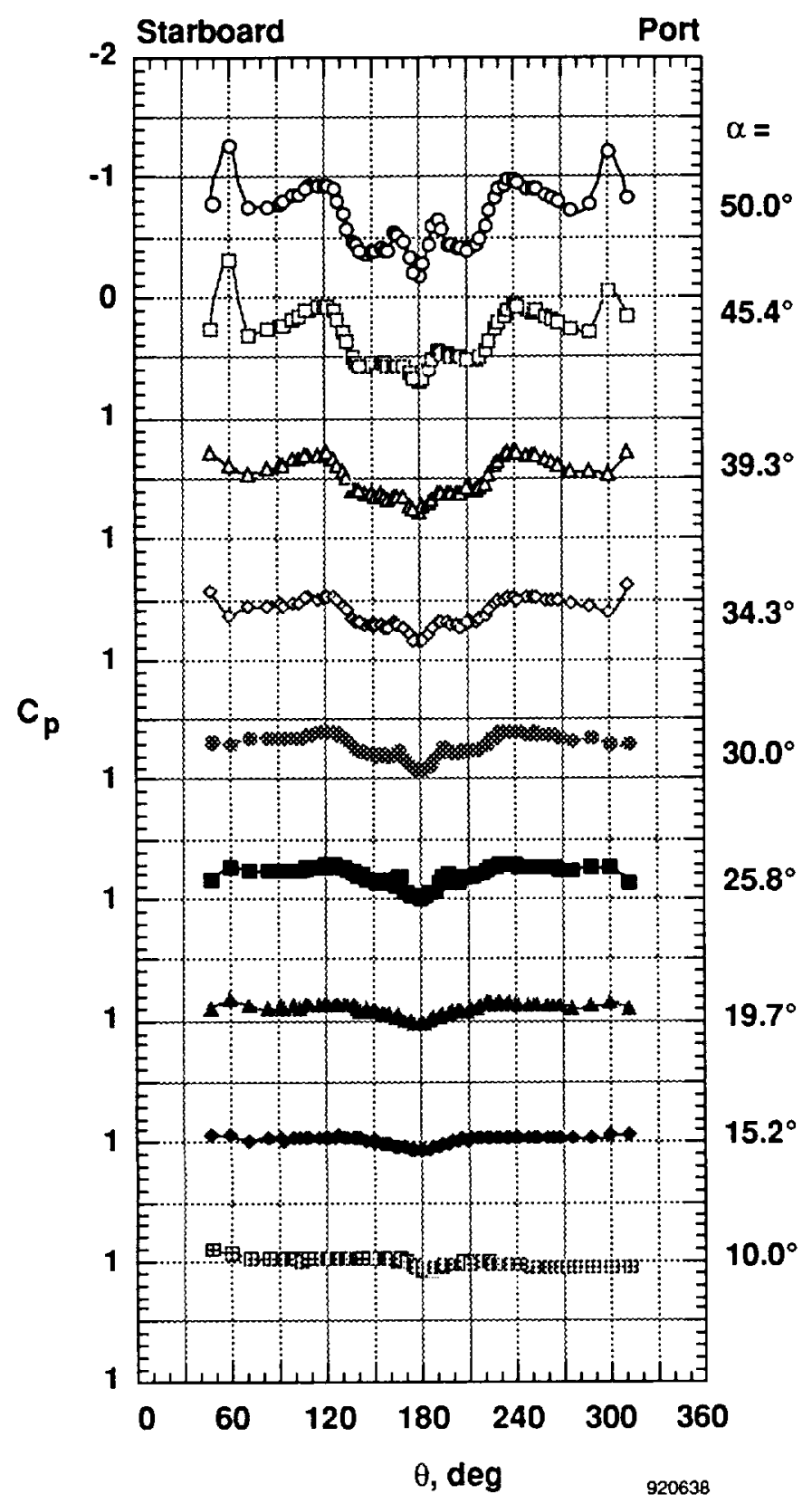

(e) $x / \ell=0.190$.

Fig. 15 Concluded.

the port vortex is closer to the surface. This asymmetry switches to starboard at $59.1^{\circ} \leq \alpha \leq 66.2^{\circ}$.

The three aft forebody pressure rows $(x / \ell=$ 0.056 , 0.136, and 0.201) (Figs. 16(b)-(d)) are behind the nose strakes and therefore have the maximum suction peaks caused by the flow accelerating around the forebody. The suction peaks caused by the nose strake vortices diminish in magnitude the farther aft the measurement location is. The angular location of the vortex footprints is $\theta \approx$ $140^{\circ}$ and $220^{\circ}$ at $x / \ell=0.056$ (Fig. 16(b)) and $\theta$ $\approx 160^{\circ}$ and $200^{\circ}$ at $x / \ell=0.136$ (Fig. 16(c)) and 0.201 (Fig. 16(d)). The reduction in magnitude of the peaks is caused by the vortex lifting away from the surface. The onset of asymmetries in the pressure distribution is also delayed as the measurement location moves farther aft. At $x / \ell=0.056$ (Fig. 16(b)), asymmetries appear at $\alpha=49.7^{\circ}$ with the higher magnitudes on the port side. At $\alpha=66.2^{\circ}$, the pressure distribution is nearly symmetric again. At $x / \ell=$ 0.136 (Fig. 16(c)), the port asymmetries start at $\alpha=$ $54.7^{\circ}$ and switch to starboard at $\alpha=66.2^{\circ}$.

To determine if the asymmetries seen in the pressure distributions contributed to the total aircraft yawing moment at zero sideslip, the pressure distributions were integrated over the projected side area. The resultant forebody yawing moment coefficient, $C_{n_{f b}}$, was plotted as a function of sideslip. A line was faired through the data and the intercept, $C_{n_{0, f b}}$, was determined. Figure 17 shows the total aircraft yawing moment coefficient ${ }^{1}$ and the forebody yawing moment coefficient plotted as a function of angle of attack. The large right aircraft yawing moment at zero sideslip at $\alpha=45.0^{\circ}$ did not correlate with the forebody pressures. However, there is a good correlation between total aircraft and forebody yawing moments at $\alpha \geq 50.0^{\circ}$.

The forebody yawing moments at zero sideslip were broken down further by individual orifice stations to determine which regions contributed to the yawing moment. Figure 18 shows the yawing moments at $\beta=0^{\circ}$ for a unit length of fuselage at each station as a function of angle of attack. The effect for the most forward row $(x / \ell=0.026)$ is small partly because of its small minor diameter (height) and partly because of the nose strake. At $\alpha \geq 55.0^{\circ}$, the second and third forebody stations $(x / \ell=0.056$ and 0.136 ) have the most effect on the forebody yawing moment to the left. The most aft forebody station $(x / \ell=0.201)$ has less effect at $\alpha \geq 55.0^{\circ}$. However, there is a right (positive) yawing moment shown at $x / \ell=0.201$ at $\alpha=45.0^{\circ}$. This suggests that the nose-right yawing of the aircraft at $\alpha \approx 45.0^{\circ}$ is affected by pressures on a region aft of $x / \ell=0.201$ (where there was no instrumentation). ${ }^{5}$ 


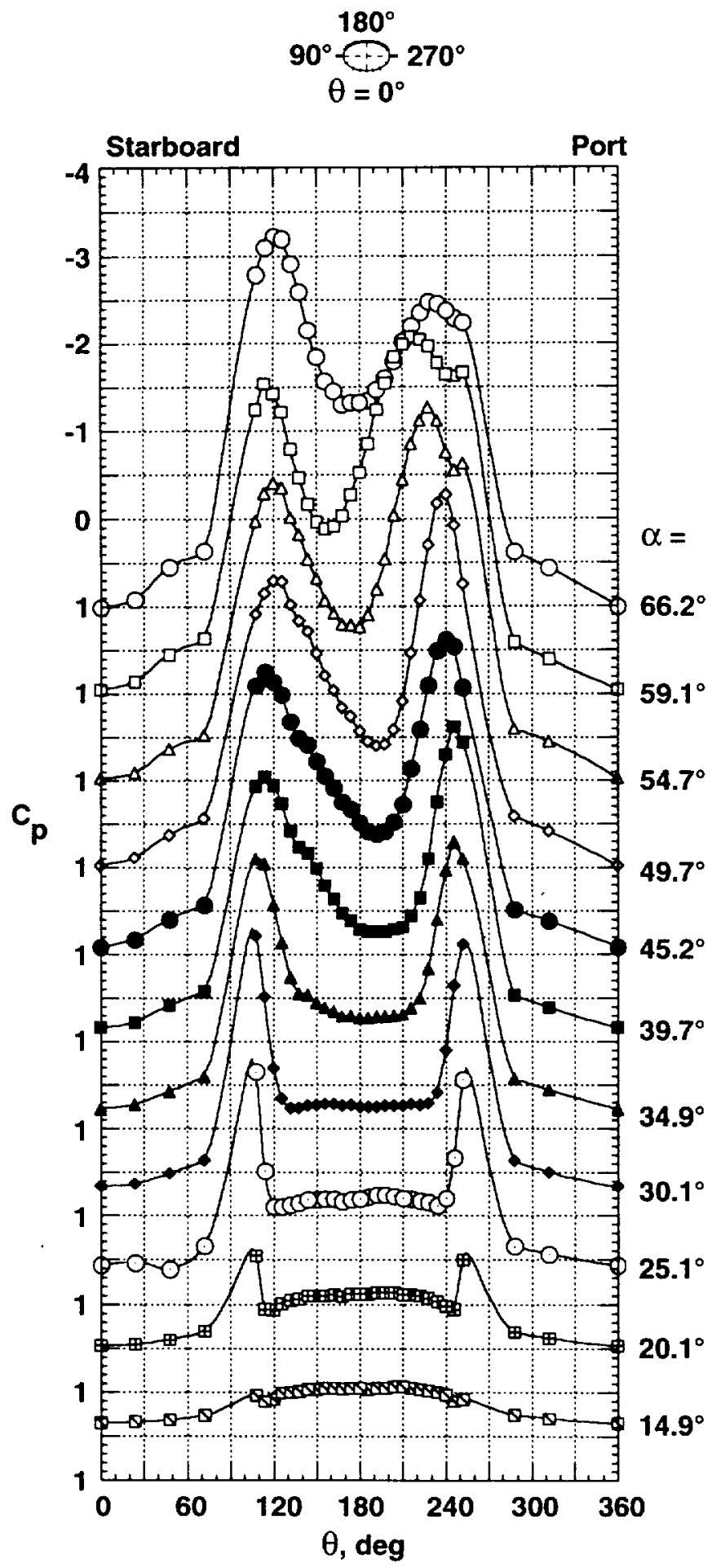

(a) $x / \ell=0.026$.
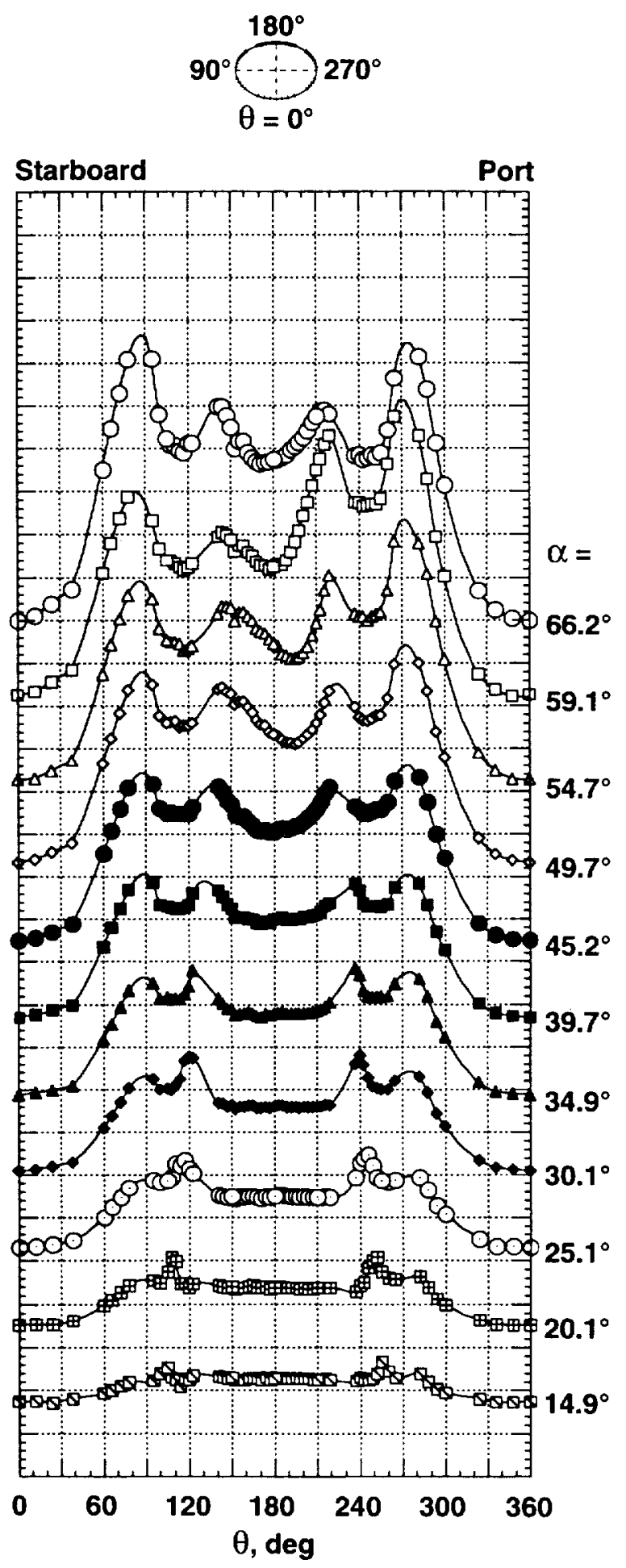

(b) $x / \ell=0.056$.

Fig. 16 Effect of angle of attack on X-29A forebody pressures. 


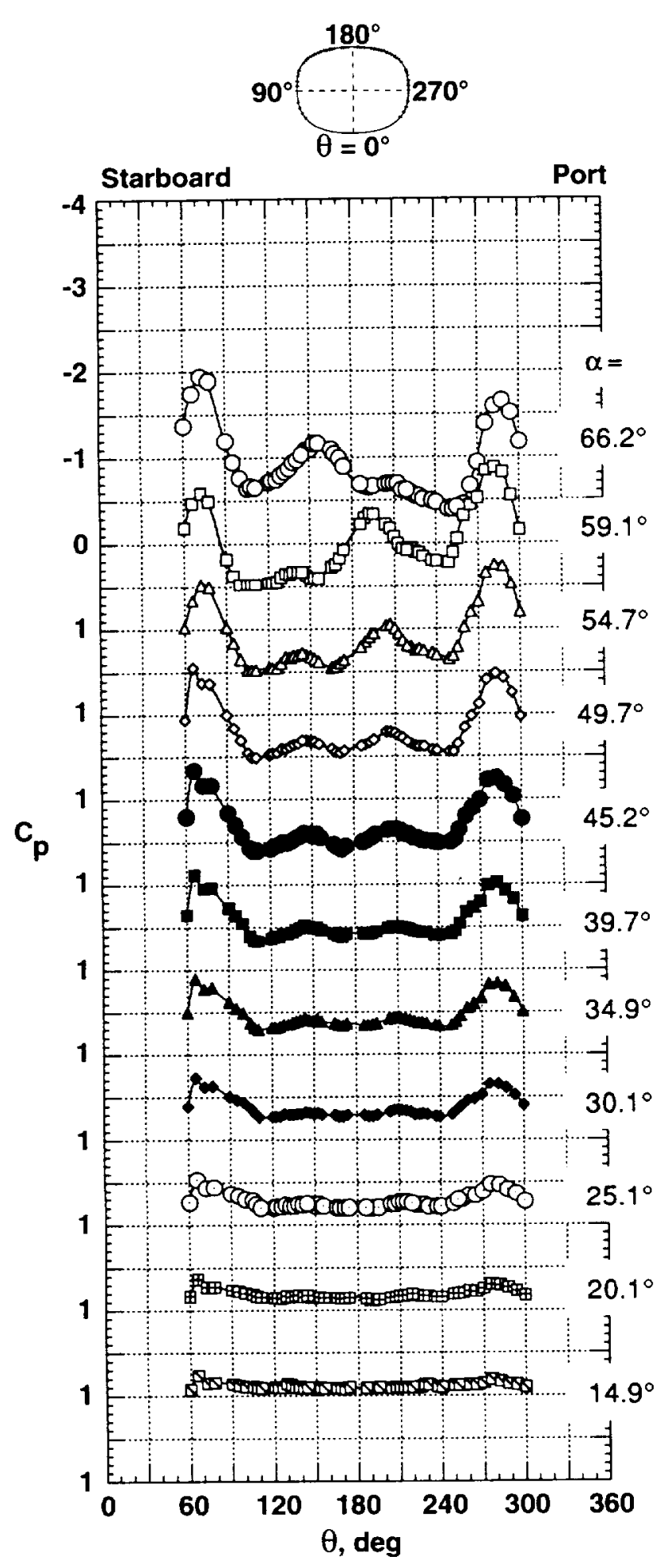

(c) $x / \ell=0.136$.

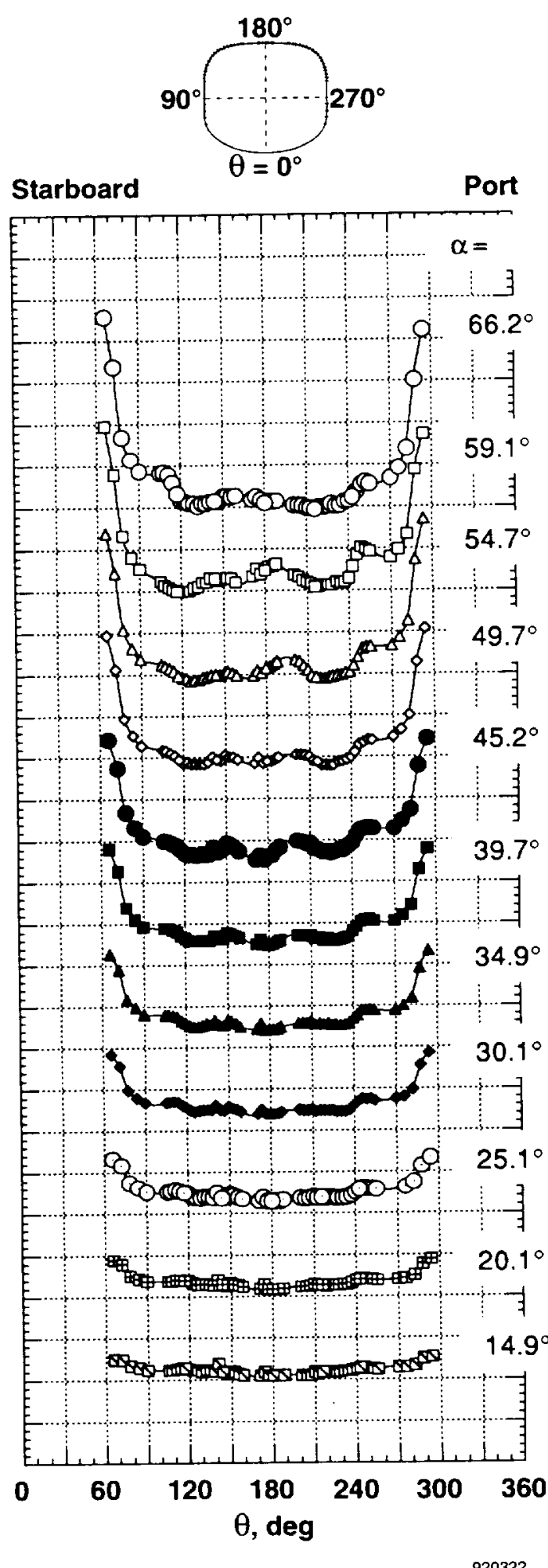

(d) $x / \ell=0.201$.

Fig. 16 Concluded. 


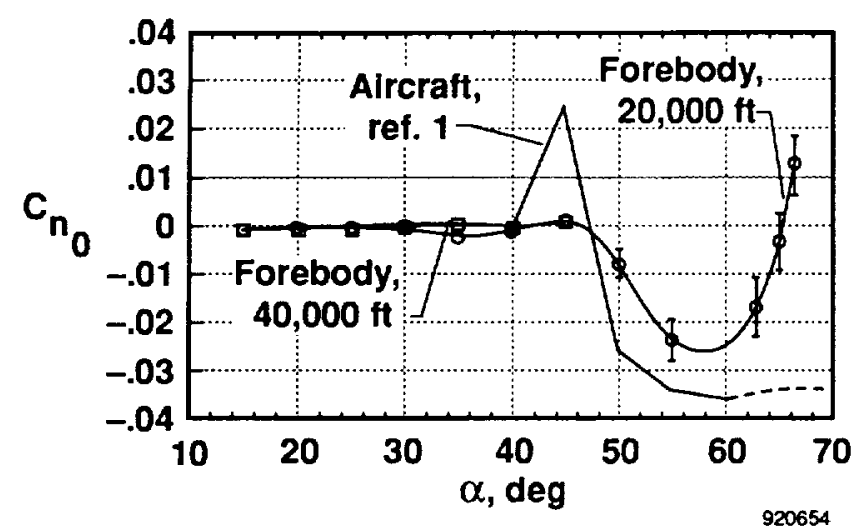

Fig. $17 X-29 A$ aircraft and forebody yawing moments at $\beta=0^{\circ}$.

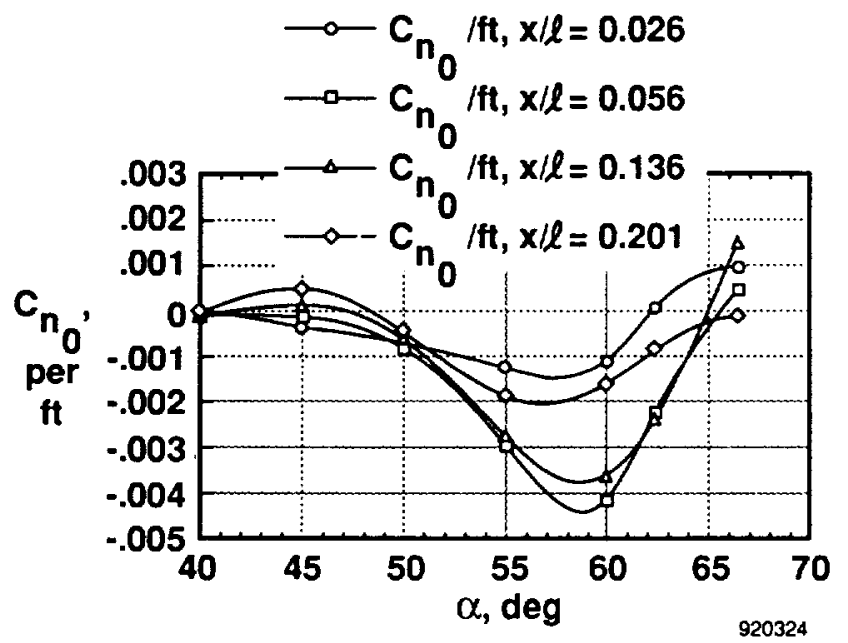

Fig. 18 Effect of angle of attack on X-29A forebody station yawing moment per unit length.

\section{CONCLUDING REMARKS}

Aerodynamic studies have been conducted at high angles of attack on the F-18 High Alpha Research Vehicle (HARV) and X-29A aircraft. Data obtained include on- and off-surface flow visualization and pressure measurements. These results can be correlated with wind-tunnel and computational fluid dynamics (CFD) results. In the case of the X-29A aircraft, the forebody results correlate well with measured aircraft results and help explain differences from predictions. Some differences were observed in the forebody aerodynamics of the two aircraft.

The F-18 HARV pressure distributions were symmetric at zero sideslip. This symmetry was also observed in the surface flow visualization. On the other hand, the X-29A pressure distributions were asymmetric at angles of attack $(\alpha)>30^{\circ}$; this correlated with flight-measured yaw asymmetries.

The F-18 HARV forebody vortices visualized were fairly well defined with distinct cores. At nonzero sideslips, the windward vortex core lifted away from the aircraft surface while the leeward vortex core was drawn into the leading-edge extension (LEX) vortex. The X-29A forebody vortices were more diffuse and nonzero sideslips tended to shift as a pair when viewed from the tail. The location of the X-29A forebody vortex cores at zero sideslip correlated well with flight-measured yawing moment asymmetries. The nose strakes and noseboom on the X-29A forebody may be partly responsible for the diffusion of the forebody vortex cores.

\section{NOMENCLATURE}

$C_{n} \quad$ yawing moment coefficient (positive right)

$C_{n_{f b}} \quad$ forebody yawing moment coefficient determined from integration of forebody pressure over projected side area

$C_{n_{0}} \quad$ yawing moment coefficient at zero sideslip

$C_{n_{0}, f b} \quad$ forebody yawing moment coefficient at zero sideslip, $\beta=0^{\circ}$ intercept of $C_{n_{f b}}$ as a function of angle-ofsideslip curve

$C_{p} \quad$ pressure coefficient

HARV

HATP

LEX

LSB

$\ell$

PGME propylene glycol monomethyl ether

$x$

distance from nose apex along longitudinal axis of aircraft (positive aft)

$\alpha$

aircraft angle of attack, deg aircraft angle of sideslip, deg forebody circumferential angle, deg $\left(0^{\circ}\right.$ is bottom centerline, positive is clockwise as seen from a front view, $0^{\circ}$ to $360^{\circ}$ )

$\theta_{v}$ angular location of the midplane between the right- and left-forebody vortices, deg $\left(0^{\circ}\right.$ is top center, positive right as viewed from the back of the aircraft) 


\section{REFERENCES}

${ }^{1}$ Webster, Fredrick R. and Purifoy, Dana, X-29A High Angle of Attack Flying Qualities, AFFTCTR-91-15, July 1991.

${ }^{2}$ Fisher, David F., Del Frate, John H., and Richwine, David M., In-FlightFlow Visualization Characteristics of the NASA F-18 High Alpha Research Vehicle at High Angles of Attack, NASA TM-4193, 1990. Also published as SAE 892222, Sept. 1989.

${ }^{3}$ Del Frate, John H., Fisher, David F., and Zuniga, Fanny A., In-Flight Flow Visualization with Pressure Measurements at Low Speeds on the NASA F-18 High Alpha Research Vehicle, NASA TM-101726, 1990. Also published in Vortex Flow Aerodynamics, AGARD-CP-494, paper no. 13.

${ }^{4}$ Fisher, David F., Banks, Daniel W., and Richwine, David M., F-18 High Alpha Research Vehicle Surface Pressures: Initial In-Flight Results and Correlation with Flow Visualization and Wind-Tunnel Data, NASA TM-101724, 1990. Also published as AIAA-90-3018, Aug. 1990.

${ }^{5}$ Fisher, David F., Richwine, David M., and Landers, Stephen, "Correlation of Forebody Pressures and Aircraft Yawing Moments on the X-29A Aircraft at High Angles of Attack," AIAA-92-4105, Aug. 1992.

${ }^{6}$ Del Frate, John H. and Saltzman, John A., "InFlight Flow Visualization Results From the X-29A Aircraft at High Angles of Attack," AIAA-92-4102, Aug. 1992.

${ }^{7}$ Moes, Timothy $R$. and Whitmore, Stephen A., A Preliminary Look at Techniques Used to Obtain Airdata From Flight at High Angles of Attack, NASA TM-101729, 1990.

${ }^{8}$ Whitmore, Stephen A., Moes, Timothy R., and Larson, Terry J., Preliminary Results From a Subsonic High Angle-of-Attack Flush Airdata Sensing (HI-FADS) System: Design, Calibration, and Flight Test Evaluation, NASA TM-101713, 1990. Also published as AIAA-90-0232, Jan. 1990.
${ }^{9}$ Moore, M. and Frei, D., "X-29A Forward Swept Wing Aerodynamic Overview," AIAA-831834, July 1983.

${ }^{10}$ Frei, Douglas, Garelick, Melvin, Hendrickson, Ronald, and Spacht, Glenn, Forward Swept Wing Study, AFFDL-TR-79-3151, Jan. 1980.

${ }^{11}$ Richwine, David M., Curry, Robert E., and Tracy, Gene V., A Smoke Generator System for Aerodynamic Flight Research, NASA TM-4137, 1989.

${ }^{12}$ Curry, Robert E. and Richwine, David M., "An Airborne System for Vortex Flow Visualization on the F-18 High-Alpha Research Vehicle," AIAA-88-4671, Sept. 1988.

${ }^{13}$ Fisher, David F., Richwine, David M., and Banks, Daniel W., Surface Flow Visualization of Separated Flows on the Forebody of an F-18 Aircraft and Wind-Tunnel Model, NASA TM-100436, 1988. Also published as AIAA-88-2112, May 1988.

${ }^{14}$ Belevtsov, N., Brumby, R.E., and Hughes, J.P., "In-Flight Flow Visualization, A Fluid Approach," 14th Annual Symposium Proceedings of the Society of Flight Test Engineers, Aug. 1983, pp. 4.2-1 to 4.2-7.

${ }^{15}$ Hughes, J.P., Brumby, R.E., and Belevtsov, N., "Flow Visualization From the Ground Up - for Aircraft Fuselages," AIAA-83-2691, Nov. 1983.

${ }^{16}$ Rajczewski, David M., Capt., "X-29A High Angle-of-Attack Flight Test: Air Data Comparisons of an Inertial Navigation System and Noseboom Probe," 21st Annual Symposium Proceedings of the Society of Flight Test Engineers, Aug. 1990, pp. 4.51 to $4.5-12$.

${ }_{17}$ Pellicano, Paul, Krumenacker, Joseph, and Vanhoy, David, "X-29A High Angle-of-Attack Flight Test Procedures, Results, and Lessons Learned," 21st Annual Symposium Proceedings of the Society of Flight Test Engineers, Aug. 1990, pp. 2.4-1 to 2.4-24. 
Public reporting burden for this collection of information is estimaled to average 1 hour per response, including the time lor reviewing instructions, searching existing data sources. Public reporting burden lor this collection of gathering and maintalning the data needed, an cor

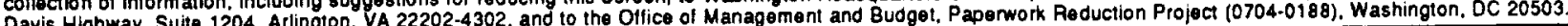

\begin{tabular}{l|l|l|} 
1. AGENCY USE ONLY (Leave blank) & 2. REPORT DATE & 3. REPOAT TYPE AND DATES COVERED
\end{tabular} November $1992 \quad$ Technical Memorandum

4. TITLE AND SUBTITLE 5. FUNDING NUMBERS

A Summary of the Forebody High-Angle-of-Attack Aerodynamics Research on the F-18 and the X-29A Aircraft

WU 505-68-71

6. AUTHOR(S)

WU 533-02-38

Lisa J. Bjarke, John H. Del Frate, and David F. Fisher

7. PERFORMING ORGANIZATION NAME(S) AND ADDRESS(ES)

NASA Dryden Flight Research Facility

P.O. Box 273

Edwards, Califomia 93523-0273

9. SPONSORING/MONITORING AGENCY NAME(S) AND ADDRESS(ES)

10. SPONSORING/MONITORING AGENCY REPORT NUMBER

National Aeronautics and Space Administration

Washington, DC 20546-0001

NASA TM-104261

11. SUPPLEMENTARY NOTES

Prepared as SAE 921996 for presentation at the Society of Automotive Engineers Aerotech ' 92 conference, Anaheim, California, October 5-8, 1992

12a. DISTRIBUTION/AVAILABILITY STATEMENT

12b. DISTRIBUTION CODE

Unclassified - Unlimited

Subject Category 02

13. ABSTRACT (Maximum 200 words)

High-angle-of-attack aerodynamic studies have been conducted on both the F-18 High Alpha Research Vehicle (HARV) and the X-29A aircraft. Data obtained include on- and off-surface flow visualization and static pressure measurements on the forebody. Comparisons of similar results are made between the two aircraft where possible. The forebody shapes of the two aircraft are different and the X-29A forebody flow is affected by the addition of nose strakes and a flight test noseboom. The forebody flow field of the F-18 HARV is fairly symmetric at zero sideslip and has distinct, well-defined vortices. The X-29A forebody vortices are more diffuse and are sometimes asymmetric at zero sideslip. These asymmetries correlate with observed zero-sideslip aircraft yawing moments.

14. SUBJECT TERMS

F-18 HARV; Forebody pressure distribution; High angle of attack; In-flight flow visualization; Vortex flow; X-29A aircraft
15. NUMBER OF PAGES 20

16. PRICE CODE

$\mathrm{A03}$

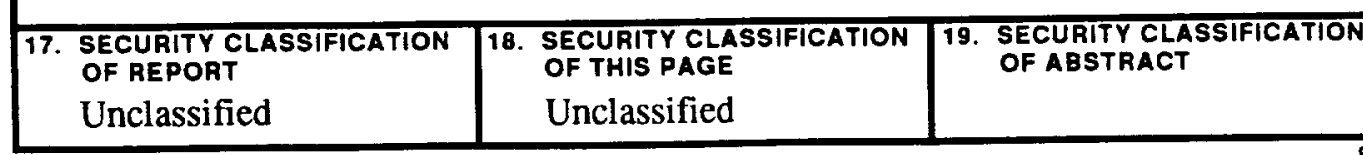

NSN 7540-01-280-5500
Standard Form 298 (Rev. 2-89) Prencribed by ANSI Std. Z30-18 298-102 